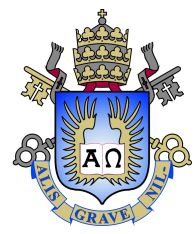

Ana Sofia Viotti Daker Aranha

\title{
Risk-constrained Optimal Dynamic Trading Strategies Under Short- and Long-term Uncertainties
}

Dissertation presented to the Programa de Pós-graduação em Engenharia Elétrica of PUC-Rio in partial fulfillment of the requirements for the degree of Mestre em Engenharia Elétrica.

Advisor : Prof. Alexandre Street de Aguiar

Co-advisor:

Dr. Sérgio Granville 


\title{
Risk-constrained Optimal Dynamic Trading Strategies Under Short- and Long-term Uncertainties
}

\begin{abstract}
Dissertation presented to the Programa de Pós-graduação em Engenharia Elétrica of PUC-Rio in partial fulfillment of the requirements for the degree of Mestre em Engenharia Elétrica. Approved by the Examination Committee:
\end{abstract}

Prof. Alexandre Street de Aguiar

Advisor

Departamento de Engenharia Elétrica - PUC-Rio

Dr. Sérgio Granville

PSR

Prof. Brundo Fanzeres dos Santos

Departamento de Engenharia Industrial - PUC-Rio

Prof. Davi Michel Valladão

Departamento de Engenharia Industrial - PUC-Rio

Prof. Francisco Muñoz Espinoza 
All rights reserved.

Ana Sofia Viotti Daker Aranha

Graduated in electrical engineering from the Pontifical Catholic University of Rio de Janeiro, with an emphasis on Energy Systems. In 2018, she started her master's program in electrical engineering at the same university. During these years she worked at PSR Energy Consulting and has been involved in studies and development of computational models in the following areas: (i) long-term energy demand forecasting; (ii) optimization of PPAs and power plants portfolios for national and international agents; (iii) quantification of financial risks in the electricity sector.

Bibliographic data

Aranha, Ana Sofia Viotti Daker

Risk-constrained Optimal Dynamic Trading Strategies Under Short- and Long-term Uncertainties / Ana Sofia Viotti Daker Aranha; advisor: Alexandre Street de Aguiar; coadvisor: Sérgio Granville. - 2021.

63 f: il. color. ; $30 \mathrm{~cm}$

Dissertação (mestrado) - Pontifícia Universidade Católica do Rio de Janeiro, Departamento de Engenharia Elétrica, 2021.

Inclui bibliografia

1. Engenharia Elétrica - Teses. 2. Comercialização de energia. 3. Seleção de portfólio. 4. Gerenciamento de risco. 5. Otimização dinâmica estocástica. 6. Árvore de decisão. I. Street, Alexandre. II. Granville, Sérgio. III. Pontifícia Universidade Católica do Rio de Janeiro. Departamento de Engenharia Elétrica. IV. Título.

CDD: 621.3 


\section{Acknowledgments}

First of all, I would like to thank my family, for all their love and affection. To my father, who inspires me everyday, for making my academic journey possible. To my mother, for being the best example of a woman I could ever have. I am immensely grateful to my brother, who through good pieces of advice helped me to start the process of writing this document. To my boyfriend, for all his patience during this period, and for all moments that make me so happy, and give me energy to go through difficult situations.

To my friends, who during this period so often heard "I can't today", for their patience. In particular, my sincere thanks to my great friends Paula Aleixo and Felipe Nazaré, who directly helped me with this work, with reviews and insights.

To my advisor, Professor Alexandre Street, who with calm, patience, wisdom and good humor was an exceptional guide, and taught me so much. His enthusiasm and ability to transmit knowledge were essential to my education. To my co-supervisor, Sérgio Granville, whom I have so much admiration for, for the many discussions and direct contributions to the developed methodology. I also thank Professor Cristiano Fernandes, not only for his contributions and efficient reviews, but for his support and encouragement during this work.

To the PSR company, for providing a rich information and knowledge environment. To the great Mário Veiga, for creating the methodology used here. I will be eternally grateful for the job opportunity that changed my life and constantly provides so many opportunities for personal and professional growth. To Luiz Augusto Barroso, for the available time for important conversations and directions.

To my boss and mentor Edmundo Grune, for being an exceptional example of professional, whom I look up to and hope to resemble one day. Thank you for providing a day by day full of learning and motivation.

To the professors participating in the examining committee, for the kindness of accepting this invitation.

This study was financed in part by the Coordenação de Aperfeiçoamento de Pessoal de Nível Superior - Brasil (CAPES) - Finance Code 001. 


\section{Abstract}

Aranha, Ana Sofia Viotti Daker ; Street, Alexandre (Advisor); Granville, Sérgio (Co-Advisor). Risk-constrained Optimal Dynamic Trading Strategies Under Short- and Long-term Uncertainties. Rio de Janeiro, 2021. 63p. Dissertação de Mestrado Departamento de Engenharia Elétrica, Pontifícia Universidade Católica do Rio de Janeiro.

Recent market changes in power systems with high renewable energy penetration highlighted the need for complex profit maximization and protection against price volatility and generation uncertainty. This work proposes a dynamic model to represent sequential decision making in this current scenario. Unlike previously reported works, we contemplate uncertainties in both strategic (long-term) and operational (short-term) levels, all considered as pathdependent stochastic processes. The problem is represented as a multistage stochastic programming model in which the correlations between inflow forecasts, renewable generation, spot and contract prices are accounted for by means of interconnected long- and short-term decision trees. Additionally, risk aversion is considered through intuitive time-consistent constraints. A case study of the Brazilian power sector is presented, in which real data was used to define the optimal trading strategy of a wind power generator, conditioned to the future evolution of market prices. The model provides the trader with useful information such as the optimal contractual amount, settlement timing, and term. Furthermore, the value of this solution is demonstrated when compared to state-of-the-art static approaches using a multistage-based certainty equivalent performance measure.

\section{Keywords}

Energy trading; Multistage stochastic optimization; Portfolio selection; Risk management; Time-consistent risk measures. 


\section{Resumo}

Aranha, Ana Sofia Viotti Daker ; Street, Alexandre; Granville, Sérgio. Otimização de Estratégias Dinâmicas de Comercialização de Energia com Restrições de Risco sob Incertezas de Curto e Longo Prazo. Rio de Janeiro, 2021. 63p. Dissertação de Mestrado - Departamento de Engenharia Elétrica, Pontifícia Universidade Católica do Rio de Janeiro.

Mudanças recentes em mercados de energia com alta penetração de fontes renováveis destacaram a necessidade de estratégias complexas que, além de maximizar o lucro, proporcionam proteção contra a volatilidade de preços e incerteza na geração. Neste contexto, este trabalho propõe um modelo dinâmico para representar a tomada de decisão sequencial no cenário atual. Ao contrário de trabalhos relatados anteriormente, este método fornece uma estrutura para considerar as incertezas nos níveis estratégico (longo prazo) e operacional (curto prazo) simultaneamente. É utilizado um modelo de programação estocástica multiestágio em que as correlações entre previsões de vazão, geração renovável, preços spot e preços contratuais são consideradas por meio de uma árvore de decisão multi-escala. Além disso, a aversão ao risco do agente comercializador é considerada por meio de restrições intuitivas e consistentes no tempo. É apresentado um estudo de caso do setor elétrico brasileiro, no qual dados reais foram utilizados para definir a estratégia ótima de comercialização de um gerador de energia eólica, condicionada à evolução futura dos preços de mercado. O modelo fornece ao comercializador informações úteis, como o montante contratado ideal, além do momento ótimo de negociação e duração dos contratos. Além disso, o valor desta solução é demonstrado quando comparado a abordagens estáticas, através de uma medida de desempenho baseada no equivalente de certo do problema multiestágio.

\section{Palavras-chave}

Comercialização de energia; Seleção de portfólio; Gerenciamento de risco; Otimização dinâmica estocástica; Árvore de decisão. 


\section{Table of contents}

$\begin{array}{llr}1 & \text { Introduction } & 14\end{array}$

$\begin{array}{lll}1.1 & \text { Motivation and Literature Review } & 14\end{array}$

$\begin{array}{lll}1.2 & \text { Contributions } & 16\end{array}$

$\begin{array}{lll}1.3 & \text { Work Organization } & 17\end{array}$

2 Principles of Energy Trading 18

$\begin{array}{lll}2.1 & \text { Spot Market } & 18\end{array}$

$\begin{array}{ll}2.2 & \text { Derivative Markets } \\ & 19\end{array}$

2.3 Overview of the Brazilian Electricity Market 23

3 Uncertainty Modeling $\quad 26$

3.1 Short-term Uncertainties 26

3.2 Long-term Uncertainties 30

3.3 Combining Uncertainties: a Proposed Framework 32

4 Risk Aversion $\quad 36$

4.1 Characterizing Risks 36

4.2 Risk Measures 37

4.3 Time-consistency in Risk Averse Dynamic Stochastic Programming 39

4.4 Risk Policy Modeling: A Proposed Framework 41

5 Portfolio Optimization Problem 43

6 Performance Measure $\quad 46$

6.1 Motivation 46

6.2 Preference Functional 47

6.3 Comparing Static and Dynamic Solutions 48

7 Case Study $\quad 50$

$\begin{array}{lll}7.1 & \text { Input Data } & 50\end{array}$

7.2 Trading Strategy and Numerical Results 52

7.3 Assessing the Value of Solutions Under a Risk-aversion Profile 55

$\begin{array}{lll}8 & \text { Conclusions } & 58\end{array}$

$\begin{array}{ll}\text { Bibliography } & 59\end{array}$ 


\section{List of figures}

Figure 2.1 Expected hourly spot prices in the Brazilian system, considering high renewable penetration.

Figure 2.2 Brazilian electricity matrix in 2021 [1]. 23

Figure 3.1 Hourly spot price and generation profiles. 30

Figure 3.2 "Here and now" versus "wait and see" strategies. 31

Figure 3.3 Tree paths and scenario distributions by cluster (node). 34

Figure 4.1 VaR and CVaR risk metrics applied to illustrative outcome density function. $\quad 39$

Figure 4.2 Return tree for asset 2. 40

Figure 4.3 Time-consistent risk constraints. 41

Figure 7.1 Expected values of wind power generation and spot prices. 51

Figure 7.2 Weekly and monthly forward contracts. 52

Figure 7.3 Dynamic (a) and static (b) trading strategies under a multistage perspective. 53

Figure 7.4 Monthly revenue quantile function for multistage and two-stage strategies. $\quad 55$

Figure 7.5 Monthly revenue quantile function for "Very high" path. 56

Figure 7.6 Preference functional. 57 


\section{List of tables}

Table 2.1 Illustrative example of physically delivered forward contract financial outcome

Table 2.2 Illustrative example of NDF financial outcome

Table 3.1 Impact of spot price and renewable production correlation in daily spot clearing

Table 7.1 Statistical strategy results by path 


\section{List of Abreviations}

VaR - Value-at-Risk

CVaR - Conditional-Value-at-Risk

W CVaR - Stage-wise Conditional-Value-at-Risk

M CVaR - Monthly Aggregated Conditional-Value-at-Risk

SDDP - Dual Dynamic Stochastic Programming

NDF - Non-Deliverable Forward

MME - Ministry of Energy and Mines

BBCE - Brazilian Power Trading Counter 


\section{Nomenclature}

\section{Sets and Indexes}

$\mathcal{C} \quad$ Set of forward contracts $c$.

$\mathcal{C}^{b u y}$ Set of energy buying forward contracts $c$.

$\mathcal{C}^{\text {ndfbuy }}$ Set of energy buying NDF contracts $c$.

$\mathcal{C}^{\text {ndfsell }}$ Set of energy buying NDF contracts $c$.

$\mathcal{C}^{\text {sell }}$ Set of energy selling forward contracts $c$.

$\mathcal{H}_{t} \quad$ Set of hours $h$ in stage $t$.

$\mathcal{L} \quad$ Set of leaf nodes $l$, where $L \subset \mathcal{N}$.

$\mathcal{N} \quad$ Set of tree nodes $n$.

$\mathcal{N}_{t} \quad$ Set of tree nodes $n$ on stage $t$.

$\mathcal{P} \quad$ Set of plants $i$.

$\mathcal{S} \quad$ Set of scenarios $s$.

$\mathcal{S}_{n} \quad$ Set of scenarios $s$ at node $n$.

$\mathcal{T} \quad$ Set of stages (weeks) $t$.

\section{Parameters}

$\alpha \quad$ Confidence level used in CVaR calculation.

$\tau_{c} \quad$ Decision stage of contract $c$.

$\tau_{c}^{e n d} \quad$ Final stage of the delivery period for contract $c$.

$\tau_{c}^{\text {start }}$ Initial stage of the delivery period for contract $c$.

$\theta \quad$ Maximum one-stage drawdown.

$C_{i} \quad$ Unitary cost of generating unit $i$, in $\mathrm{R} \$ / \mathrm{MWh}$.

$E_{i, h} \quad$ Firm energy certificate of unit $i$, in hour $h$, in MWh. 
$F_{c, n} \quad$ Price, in $\mathrm{R} \$ / \mathrm{MWh}$, of contract $c$, at node $n$.

$G_{i, s, h}$ Generation of unit $i$, scenario $s$, in hour $h$, in MWh.

$n(s, t)$ Node containing scenario $s$ in stage $t$. Denoted as $n$ for simplification.

$P_{s} \quad$ Probability of scenario $s$.

$Q_{c, h}$ Maximum energy volume, in MWh, of candidate contract $c$, in hour $h$.

$R_{\text {min }}^{J}$ Minimum CVaR allowed by week, if $J=w$ or month, if $J=l$.

$S_{s, h} \quad$ Spot price in scenario $s$, hour $h$, in $\mathrm{R} \$ / \mathrm{MWh}$.

$t_{n} \quad$ Stage of node $n$.

\section{Decision Variables}

$\delta_{n, s}^{J} \quad$ Auxiliary variable for CVaR computation in node $(J=w)$ or leaf $(J=l)$, that represents the left deviation of the net revenue scenario $s$ to the variable $z_{n}^{J}$.

$e_{s, t}^{l g} \quad$ Long energy position in scenario $s$, stage $t$.

$e_{s, t}^{s h} \quad$ Short energy position in scenario $s$, stage $t$.

$r_{s, t} \quad$ Net income in scenario $s$, stage $t$.

$x_{c, n} \quad$ Percent value of maximum contract volume $q(c, t)$ in node $n$.

$z_{n}^{J} \quad$ Auxiliary variable for CVaR computation that will determine the net revenue $\operatorname{VaR}$ for each node $(J=w)$ or leaf $(J=l)$ at the optimum solution.

\section{Dual Variables}

$\eta_{s, t} \quad$ Dual variable associated to the maximum drawdown constraint, defined by scenario $s$ and stage $t$.

$\gamma_{n} \quad$ Dual variables associated to the monthly aggregated CVaR constraints, defined by leaf node $n \in \mathcal{L}$.

$\lambda_{n} \quad$ Dual variables associated to the stage-wise CVaR constraints, defined by node $n$. 


\section{Introduction}

\section{1}

\section{Motivation and Literature Review}

In recent years, there has been a significant increase in renewable energy shares of energy matrices within developed and emerging countries. According to analysts, the continuing trend will result in a series of changes in energy markets [2]. More specifically, the high rate of solar and wind penetration requires an increase in time granularity of settlement periods, while the improved price signals will offer traders interesting opportunities to exploit profitability. Notwithstanding, while the expansion of intermittent renewable units will provide short-term marketing opportunities, it will also increase the complexity of agents' decision-making processes. In this setting, the increased price volatility requires more sophisticated hedging and portfolio optimization strategies.

Ever since the pioneering work of Markowitz [3], a great number of risk averse portfolio optimization frameworks have been proposed. In recent years, as defined and formulated in [4], risk is usually represented through financial metrics, namely: variance, mean-variance (Markowitz model), shortfall probability, expected shortage, Value-at-Risk (VaR), and Conditional-Value-at-Risk $(\mathrm{CVaR})$.

Relevant works in related literature, such as [5-8], use portfolio selection models to solve revenue maximization problems in the electricity market, in a risk averse setting. In [7], the mean variance Markowitz theory is extended to optimize a retailer's client portfolio, considering the VaR metric. In [5] and [8], the authors use a stochastic optimization model that maximizes the convex combination between the expected revenue and CVaR, to account for both the financial risk and return of generators. Meanwhile, [6] uses a hybrid robuststochastic optimization framework to determine the optimal renewable sources' portfolio with commitments in the forward market, also characterizing risk through a risk-adjusted objective function. Despite their relevance, the models described in [7], [8], and [6] use fixed asset allocation methods (also known as static), disregarding the fact that decisions can be postponed according to 
future market dynamics.

On this basis, this paper addresses one of the variants of portfolio optimization modeling known as a dynamic, or multistage (hereinafter used interchangeably), approach. The significance of a dynamic solution has been discussed in [9], [10,11], and [12-14], among others. A critical point of these works was the account for a decision process where investment/hedging decisions are conditioned on system state. Therefore, the fact that decision makers can take advantage of partially revealed information about uncertainties along a time horizon can be incorporated in the model. To do so, the authors in [9] use a hybrid robust-stochastic approach and create a real-option-based investment model for renewable power units considering a single yet dynamic longterm contracting opportunity. In [11], a scenario tree framework $([15,16])$ is used to outline the optimal scheduling of thermal generating units, considering electricity and gas price uncertainties. However, scenario reduction techniques $([17,18])$ are used to translate hundreds of randomly generated scenarios into a dozen, for the sake of computational tractability.

Furthermore, the characterization of risk policies in the multistage framework largely relies on single-period or nested formulations $([12,13]$ and [14]). Thus, the consideration of time-consistent risk management policies that rely on sophisticated multiperiod constraints in the multistage setting is a challenge.

Hence, the purpose of our work is to present a new methodology using multistage stochastic programming to assist risk averse agents in creating time-consistent optimal dynamic trading strategies under uncertainty. Since forward/future contracts are one of the most active and basic derivatives in electricity markets, this paper provides a procedure to determine the optimal dynamic selection of forward contracts by a power producer or trading company. In this context, agents face two types of uncertainties: short-term operational uncertainties, associated with renewable generation and spot-price volatility considered in studies such as [19-21], and long-term uncertainties associated with strategic contracting decisions and the future evolution of derivative prices.

The modeling complexity of our proposal derives from the fact that these aspects do not necessarily have the same time scale and level of unpredictability but are still coordinated. While operational targets are guided by several uncertain variables, with time steps of hours, or even minutes, strategic decisions regarding the optimal involvement in derivatives often depend on the market response to these changes within a weekly or monthly time scale. Nevertheless, to get a proper picture of the agent's risks and profitability, 
the operational time scale is needed. Optimizing this process is analytically challenging, since it requires a formulation of a multi-period contract portfolio that incorporates correlated price and generation risks, as well as coherent forward price formation, all of which stochastically evolve in path-dependent processes.

Even though there is a rich literature regarding portfolio optimization and uncertainty modeling, little attention has been paid to how short-term operational aspects may affect long-term dynamic decisions. Among all aforementioned related works, [9] is the closest to our target, since it is able to consider dynamic decisions under both types of uncertainties by using a hybrid robust-stochastic and real option approach. In such model, the stochastic and robust portion accounts for the plant production and spot price uncertainty while a mean-reverting binomial lattice is used to represent contract prices and bring the model to the dynamic world. However, the modeling is not designed to embrace multiple-investment nor multiple-contracting decisions. Furthermore, the authors use a nested-CVaR minimization to account for risk aversion, which can be a non-intuitive and difficultly interpreted risk policy.

In our model, we tackle these problems with a multistage stochastic approach and use a dual scale decision tree model [22], which jointly considers short and long-term uncertainties. As for risk averse agents, we propose multiple intuitive risk policies, such as maximum drawdown [23], and stagewise and monthly aggregated constraints using Rockafeller's representation of CVaR [24], guaranteeing the temporal consistency (optimal planned decisions are optimal in future problems for every path that uncertainties may take [13]) throughout the process and bringing flexibility to the model.

Moreover, we provide the mathematically grounded formulation of an innovative performance measure used to compare risk constrained policies under a single perspective. Hence, we are able to estimate the value of strategies with various degrees of risk aversion to an agent with a specific dynamic risk profile. Furthermore, the measure is general enough to allow comparisons between dynamic and static solutions. Accordingly, it is possible to assess the benefits of the proposed dynamic approach against the state-of-the-art static works such as $[8,25]$.

\section{2}

\section{Contributions}

In short, this work contributes to the literature on portfolio management and optimization as follows: 
1. Provides an optimal forward contracting decision support tool that accounts for both short-term (operational) and long-term (strategic) uncertainties under a multistage risk-constrained stochastic framework.

2. Considers realistic portfolios that may contain a high number of assets, such as generating units, forwards, futures and other purely financial derivatives.

3. Uses multiple intuitive and sound risk metrics to define time-consistent multistage risk-averse strategies.

4. Provides and demonstrates the validity of a performance metric for riskaverse policies. Moreover, the presented metric is general enough to allow comparisons between solutions from dynamic and static approaches.

\section{3 \\ Work Organization}

The remainder of this dissertation is organized as follows. In chapter 2 we discuss the principles of energy trading in electricity markets and give a brief overview of the Brazilian market and its undergoing changes. Chapter 3 presents a theoretical background in uncertainty modeling, differentiating the concepts of short- and long-term uncertainties. Practical examples of how each uncertainty type impacts the modeling are provided. Furthermore, a framework for combining uncertainties is proposed, detailing the trading problem and building the proper connections between inflow forecasts, renewable generation, spot prices, scenario trees, and contract pricing.

Risks in the energy trading business as well as the most customary risk measures are characterized in chapter 4. Moreover, the difficulties faced regarding risk averse dynamic programming are addressed once the issue of time-consistency is introduced. On this basis, three time-consistent risk metrics are proposed.

In chapter 5, the mathematical formulation for the portfolio optimization problem is presented. Chapter 6 validates a performance measure for the comparison of solutions from different risk-averse policies. Chapter 7 provides numerical results for a case study using realistic data from the Brazilian power sector. Finally, relevant conclusions are drawn in chapter 8. 


\section{2}

\section{Principles of Energy Trading}

The energy trading activity is not a trivial task and requires active management by its agents. In this chapter, we present the principles of electricity trading in both spot and derivative (contracting) markets. Furthermore, a brief overview of the Brazilian electricity market is presented, including aspects of its undergoing physical and regulatory changes.

\section{1}

\section{Spot Market}

The spot market is one of the core elements of electricity markets, as it determines the prices paid for energy and related services at any given time and location. Therefore, it provides the basis for electricity trading.

Depending on the market design, prices can be either formed through (i) cost-based or (ii) bid-based approaches. In (i), generators must inform the system operator of their operational costs so they can proceed to solve the problem of minimizing the overall system operational cost, without interference from any market agent. Furthermore, prices are determined by the marginal cost of operation. Conversely, in (ii) agents can bid their individual costs according to projections and studies carried out in a decentralized manner. Prices are then defined by the maximization of social welfare.

Even though these approaches are clearly distinct, the spot prices are dependent in many common variables such as the demand, fuel availability, weather conditions, transmission exchange limits between regions, etc. Not surprisingly, spot prices are, in general, subject to high volatility.

Moreover, with the recent downward trend in renewable power plants' costs, there has been a significant increase in the share of wind and solar technologies in the energy matrix of countries worldwide. This trend resulted in overall benefits to the system and the society itself, such as reduced prices and clean energy availability. In some cases, it also resulted in the requirement of an increase in time granularity of settlement periods. This change brings significant short- and long-term benefits to the system, such as improved flexibility in operations through price signals, as well as optimized investments in flexible generation capacity. Shorter market time units were 
recently explored in California (United States), Brazil, Germany and other European markets [26].

Despite the undeniable benefits of renewable resources, the growth of intermittent generation drastically impacted spot prices, leading to increased volatility. Figure 2.1 displays the forecasted spot prices for the Brazilian system in 2040, assuming a non conventional renewable installed capacity of $42 \%$ ( $28 \%$ solar and $15 \%$ wind), expansion plan foreseen by experts. The forecast was made using the Dual Dynamic Stochastic Programming (SDDP) [27], which will be discussed further in Section 3.1.2.

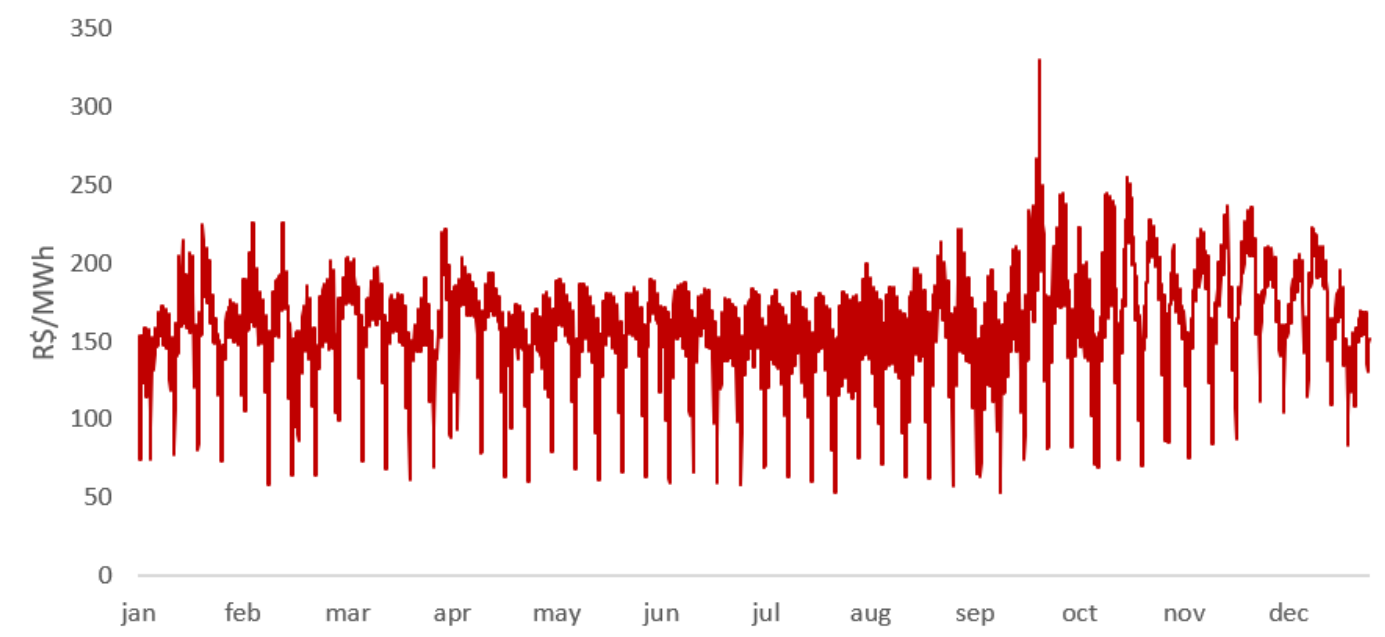

Figure 2.1: Expected hourly spot prices in the Brazilian system, considering high renewable penetration.

The increase in price volatility due to the high penetration of intermittent sources becomes clear with Figure 2.1, as they require the drive of flexible generating thermal units (usually costly) that are able to rapidly ramp output up or down as the renewable generation fluctuates, providing stability to the electric grid. The SDDP results are aligned with findings from [19] and [20].

\section{2}

\section{Derivative Markets}

One of the key takeaways of modern portfolio theory [3] introduced by Harry Markowitz is the well-known portfolio diversification practice. It is argued that asset diversification can help mitigate volatility and therefore is a great way of balancing risks. In the electricity sector, diversification can take place through physical and financial assets. Bearing in mind the purpose of this dissertation, this section is restricted to financial mechanisms: the energy derivatives. 
A derivative can be defined as a financial instrument whose value depends on (or derives from) the values of other, more basic, underlying variables [28], such as the electricity spot price. They play a key role in transferring a wide range of risks from one agent to another, but can be also used for speculation or arbitrage.

Forwards, futures, options, and swaps are examples of derivatives. Since the first two are the most liquid derivatives in electricity markets, in this section we provide an overview of how they work and how they can be used as financial hedging instruments.

\subsection{1}

\section{Conventional forwards}

Forwards are the most traditional form of derivatives, as they were the first type of contracts to be negotiated in the market. These are classified as linear derivatives, as variations in spot prices translate directly into a linear change in payoffs.

Forward contracts trading take place in the over-the-counter-market (OTC), usually negotiated bilaterally between generators, consumers, and/or trading companies. An energy selling (or short) forward contract is a commitment to deliver an amount of energy, $Q$, for a given future period, and at a given price, $F$, by either generating or buying it at the spot market. Likewise, a buying (or long) forward contract is a commitment to buy an amount of energy for a given period and at a given price, for consumption or selling in the spot market. Therefore, they provide a fix revenue (or cost) of $Q F$ for the parties involved.

These contracts can be used to lock in future prices and hedge against the spot price volatility, facilitating profit predictability. A striking difference between electricity and conventional contracts for other commodities such as oil and metals is that, for the former, delivery is specified for a period of time (weeks, months, years), while for the latter, full settlement occurs on an specific delivery date [28].

As an illustrative example, suppose that a buyer (consumer) and a seller (trading company) agree to settle a $1 \mathrm{MWh}$ forward contract for $160 \mathrm{R} \$$. Table 2.1 shows three equiprobable spot price scenarios, that lead to three possible financial outcomes for the contract holders in a specific date of the delivery period. 
Table 2.1: Illustrative example of physically delivered forward contract financial outcome

\begin{tabular}{|c|c|c|c|c|c|}
\hline \multirow[t]{2}{*}{ Scenario } & $\begin{array}{l}\text { Spot Price } \\
(\mathrm{R} \$ / \mathrm{MWh})\end{array}$ & \multicolumn{2}{|c|}{ Buyer } & \multicolumn{2}{|c|}{ Seller } \\
\hline & & Disburse: & $-160 \mathrm{R} \$$ & Disburse: & $-300 \mathrm{R} \$$ \\
\hline \multirow[t]{3}{*}{1} & 300 & Income: & - & Income: & $+160 \mathrm{R} \$$ \\
\hline & & Outcome: & $-160 R \$$ & Outcome: & $-140 \mathrm{R} \$$ \\
\hline & & Disburse: & $-160 R \$$ & Disburse: & $-100 R \$$ \\
\hline \multirow[t]{3}{*}{2} & 100 & Income: & - & Income: & $+160 \mathrm{R} \$$ \\
\hline & & Outcome: & $-160 \mathrm{R} \$$ & Outcome: & $+60 \mathrm{R} \$$ \\
\hline & & Disburse: & $-160 R \$$ & Disburse: & $-50 \mathrm{R} \$$ \\
\hline \multirow[t]{2}{*}{3} & 50 & Income: & - & Income: & $+160 \mathrm{R} \$$ \\
\hline & & Outcome: & $-160 \mathrm{R} \$$ & Outcome: & $+110 \mathrm{R} \$$ \\
\hline
\end{tabular}

In this case, the buyer worked as a hedger, by paying a risk-free amount (160 R $\$$ ) for the energy consumed. Therefore, he was able to hedge against the scenario in which the spot price assumes a high value of $300 \mathrm{R} \$ / \mathrm{MWh}$. Meanwhile, the seller acted as a speculator, since he believed spot prices would lower and he would therefore profit from buying energy in the short term market to sell it for a higher price.

Another possibility is to trade a cash-settled forward contract, in which negotiation relies strictly on price, with no necessary link to physical energy delivery. Therefore, they are also known as Non-Deliverable Forwards (NDF). This is common in negotiations between agents that do not actually need to receive the energy, such as traders and financial institutions, or generators and consumers operating with the objective of providing liquidity.

In NDFs, the settlements are calculated as the difference between the negotiated contract price and the actual spot price upon the expiration date of the transaction. Therefore, the amount to be paid by the buyer to the seller is $(F-S) Q$ if $F \geq S$, or to be received is $(S-F) Q$ if $F \leq S$.

Table 2.2 illustrates the same situation as the one described in subsection 2.2.1, in which two agents agree on settling a $1 \mathrm{MWh}$ contract for $160 \mathrm{R} \$$. However, in this case, the holders have purely financial objectives and therefore 
choose to negotiate a NDF.

Table 2.2: Illustrative example of NDF financial outcome

\begin{tabular}{cc|cccc}
\hline \multirow{2}{*}{ Scenario } & $\begin{array}{c}\text { Spot Price } \\
(\mathrm{R} \$ / \mathrm{MWh})\end{array}$ & \multicolumn{2}{|c}{ Buyer } & \multicolumn{2}{c}{ Seller } \\
\hline 1 & 300 & Disburse: & - & Disburse: & $-140 \mathrm{R} \$$ \\
& & Income: & $+140 \mathrm{R} \$$ & Income: & - \\
\hline \multirow{2}{*}{3} & 100 & Disburse: & $-60 \mathrm{R} \$$ & Disburse: & - \\
& & Income: & - & Income: & $+60 \mathrm{R} \$$ \\
\hline & 50 & Disburse: & $-110 \mathrm{R} \$$ & Disburse: & - \\
\hline
\end{tabular}

Note that the settlement of these derivatives involves a smaller financial disbursement if compared to conventional forwards with physical delivery. This characteristic brings a series of benefits to the involved parties and the market itself, such as less cash requirements, greater flexibility in risk management and, ultimately, increased market liquidity.

\subsection{2}

Futures

A lot like forward contracts, energy futures are agreements between two parties to buy or sell energy at a certain time in the future for a certain price. However, unlike forwards, they have standardized features and are traded under "exchange-traded-markets" or "organized counters". These markets connect buyers and sellers that do not necessarily know each other. Futures can be either cash-settled or physically delivery, as the exchange specify the conditions for the contracts they cover.

When traded in an exchange, the parties have the benefit of a clearing house to reduce credit risk. The clearing house mitigates risks of counterparty defaults by requiring both traders to deposit funds (known as margins) to ensure that they will comply with their obligations. Furthermore, differently from forwards, futures are marked-to-market daily, which means that there are daily settlements until the end of the contract. 


\section{3}

\section{Overview of the Brazilian Electricity Market}

The design of the power market in Brazil is heavily influenced by the presence of abundant hydropower. Among the $171 \mathrm{GW}$ of installed capacity (2021), approximately $64 \%$ of the energy is produced by hydroelectric plants, while the remaining generation mix includes wind (11\%), natural gas $(8.8 \%)$, biomass $(8.2 \%)$, solar $(2.6 \%)$, oil $(2.5 \%)$, coal $(1.8 \%)$, nuclear $(1.2 \%)$, and others $(0.4 \%)[1]$.

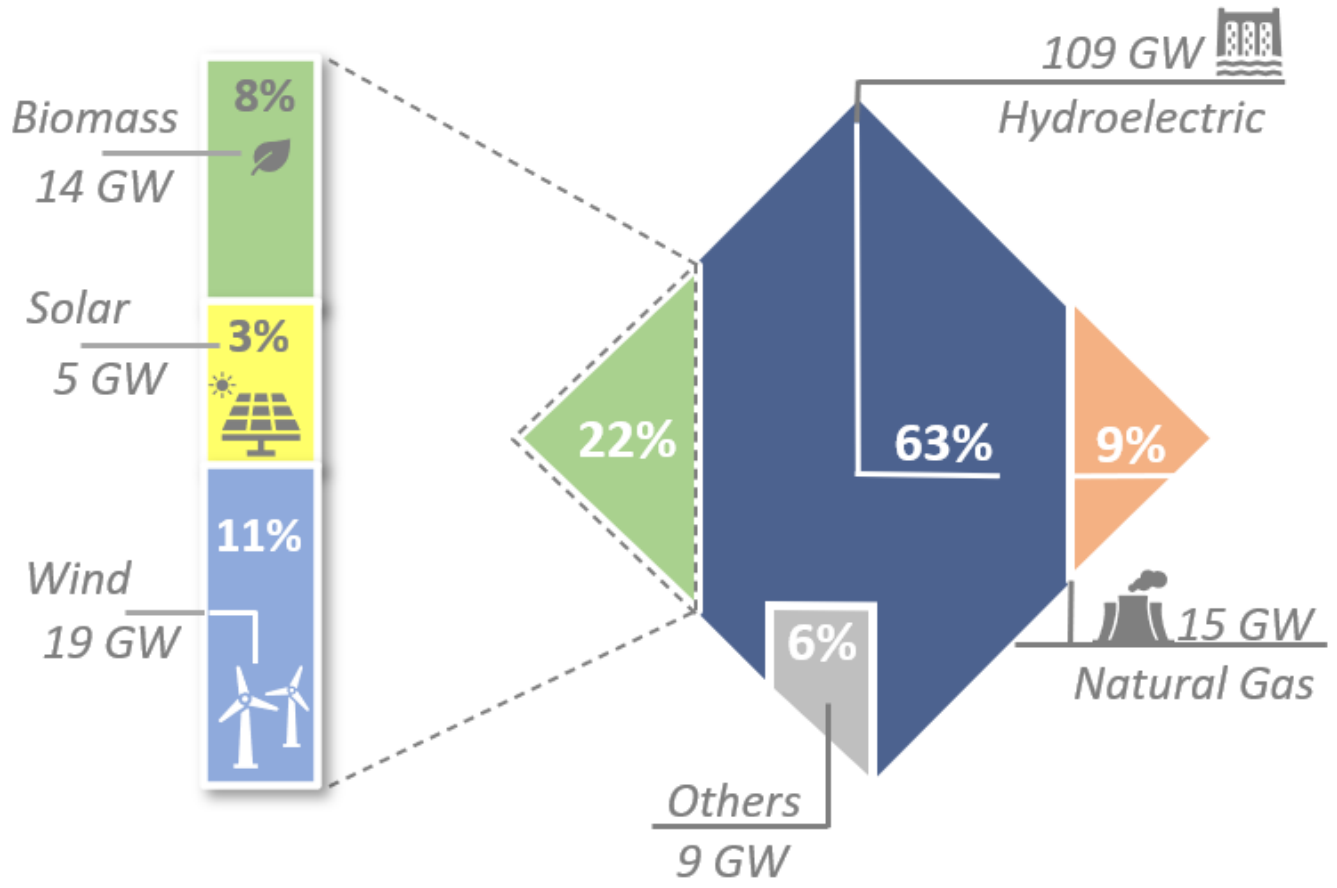

Figure 2.2: Brazilian electricity matrix in 2021 [1].

In this context, a central point of the institutional model of the Brazilian Electricity Sector is security of supply. This security is guaranteed through two basic business model rules:

1. All consumers must have $100 \%$ of their load covered by contracts.

2. All contracts must have a physical ballast of generation.

The requirement of $100 \%$ of contracting with physical ballast creates a "connection" between demand growth and the entry of new equipment. To conform with rule no. 2, the Ministry of Energy and Mines (MME) assigns each plant an amount of energy, measured in averageMW (avgMW or MWh/h), that corresponds to their sustainable production capacity. This value is known as Physical Guarantee - PhG. In general, it reflects each plant's energy 
contribution during the dry periods. The PhG (hereinafter denominated as Firm Energy Certificate) also corresponds to the maximum amount of energy that can be sold through contracts.

In July 2004, the law decree 5.163 set the basis for electricity trading in Brazil as it established two contracting market environments: (i) Regulated and (ii) Free Market. The Regulated Contracting Environment is the market segment in which electrical energy purchase and sale operations are carried out between selling and distribution agents, through energy auctions. In this environment, long-term contracts (between 20 and 30 years) are signed, facilitating project financing and therefore guide the generation expansion in Brazil. Besides, these auctions seek to allocate systemic risks (difficult for the seller to manage) to consumers.

On the other hand, in the Free Contracting Environment, contracts are bilaterally negotiated among generators, traders, and large consumers who choose to participate. Thus, consumers can freely negotiate contractual conditions with their suppliers, such as price, terms, and flexibilities. This environment grants autonomy for portfolio and risk management. Currently, it corresponds to approximately $35 \%$ of the total electricity consumption in the National Interconnected System [29]. Furthermore, the market trend indicates an increasingly accentuated growth of this share, due to the more competitive prices as opposed to the regulated ones.

Regarding the spot market, since the Brazilian system is centrally dispatched and cost-based, the spot price is calculated by means of the marginal cost of operation and represents the expected value of the water opportunity. According to the aforementioned law decree, since 2004 the spot prices in Brazil have been calculated using weekly intervals for three load tiers: peak, shoulder and valley, using a centralized computer-aided economic dispatch. In July 2017, the Public Consultation 033/2018 (CP033) proposed measures for the modernization and expansion of the electricity market. One of the main recommendations of CP033 was the increase of operation's and price's time granularity, to extend short-term flexibility. This was motivated by recent needs brought by increasing solar and wind shares and hydro's changing role in system expansion due to socio-environmental constraints of building new large hydro reservoirs [26]. In July 2019, MME decreed through the ordinance no. 301 the beginning of hourly operations starting in 2020, as well as hourly prices by 2021, which are currently in effect.

Driven by these market improvements and the continuously growing number of consumers in the Free Market, the Brazilian Stock Exchange (B3) and the Brazilian Power Trading Counter (BBCE) have recently started 
offering NDFs. Some of the advantages of these products, as noted by BBCE, include the fact that there is no need for physical delivery, and therefore no exposure to the ballast penalty; regulatory stability of the financial market, and a trading risk that is limited to the difference between the spot and contract price.

In this context, even though this dissertation focuses on conventional forward trading with physical delivery, as they still are the most "standard" and liquid derivatives in the Brazilian market, the same framework can be used for NDFs. 


\section{3 \\ Uncertainty Modeling}

Dealing with uncertainties is a challenging task, as, in practice, the limited knowledge about the future requires planners to make many assumptions. In energy portfolio models, we highlight two types of uncertainties: (i) short-term uncertainties associated to plant generation and spot prices and (ii) long-term uncertainties associated with strategic contracting decisions and the future evolution of derivative prices.

To further complicate the matter, these aspects do not necessarily have the same time scale and level of unpredictability, and therefore require different modeling techniques. For these reasons, portfolio optimization problems usually address a single type of uncertainty. On the one hand, two-stage approaches such as [6-8] are restricted to short-term uncertainty effects, while multistage works $[9,10]$ tend to focus on long-term.

In this chapter, we explore the differences between the two uncertainties and how they impact the trading strategy. Finally, we propose a method for combining both uncertainty sources into a multistage stochastic problem.

\section{1}

\section{Short-term Uncertainties}

Usually, short-term uncertainties are either represented using parametric or non-parametric approaches. While the former assumes an estimated probability distribution for the studied phenomenon, the latter allows for the representation of more complex systems, through scenario simulation techniques. One of the most traditional approaches in stochastic optimization is the wellknown Monte Carlo simulation [30]. This method is particularly appealing because it is easy to implement and remains computationally tractable for high dimensional problems. More recently, robust optimization has also gained ground on this matter [6].

In this subsection, we propose a procedure to generate a finite number of correlated inflow, renewable production, spot price and dispatch scenarios to supply a deterministic demand, based on relevant works. However, it is worth mentioning that the functioning of the decision support tool suggested in this dissertation is not limited to the following simulation method. Therefore, any 
other exogenous production and price simulation procedures can be used as input data to the tool, even though we highlight the importance of maintaining the cross dependencies between these variables.

\subsection{1}

\section{Inflow Forecasting and Renewable Generation}

For predominant hydrothermal systems such as Brazil's, hydrology is the basis to price formation. Fortunately, a log-normal can usually adequately represent the marginal distribution of inflows [30,31], while Monte Carlo based methods can be employed for scenario simulation. In this work, a periodic autoregressive model (PAR) [32] is used to reproduce the one officially operated in Brazil [33].

To select the most suitable model when it comes to renewable output prediction, the following aspects were considered:

- The framework must deliver accurate extreme scenarios, accounting for spatial and temporal correlations, which are of great importance in risk analysis;

- Non-Gaussian distributions must have consistent treatment, as it can significantly change tail risk scenarios.

For those reasons, we make use of the non-parametric Bayesian network method proposed in [31], to create synthetic hourly generation scenarios, and consider not only correlations between wind and solar units themselves, but also between wind speed, radiation, and inflows.

A Bayesian network is defined as a directed graphical model that can compactly represent the joint probability distribution of n-dimensional variables, using strictly the most important correlations between variables. Since the non-parametric approach does not assume any kind of shape for the distribution, the method will infer the distribution function from the available data. This allows a better fit for stochastic processes that are not correctly characterized by known distributions.

The authors in [31] detail the procedure used to obtain the forecasts as follows:

1. Estimate a PAR(p) model for monthly/weekly inflow forecasting and generate inflow scenarios assuming a log-normal marginal distribution. Sampling can be done through Monte-Carlo based methods;

2. For each renewable site, estimate the original distribution function by fitting the Kernel Density Estimation [34] from the historical data; 
3. Transform the non-parametric marginal distributions into series of normally distributed random variables through a method that is equivalent to implicitly choosing a Gaussian copula [35] for the random variables.

4. Apply the Bayesian network into the historical normalized data to determine the statistical dependence between variables and build regressive models in the form of $y_{t}=a_{0}+\sum_{j} a_{j} x_{j, t}+\epsilon$, where $y$ is a renewable site and $x_{i}$ can be either a different renewable site or an inflow series. Note that the renewable data must be aggregated into the same monthly/weekly time granularity as the inflows;

5. Estimate the Bayesian network parameters, using the statistical dependency structure found in (4);

6. Forecast monthly/weekly renewable scenarios using the models built in (5).

7. Transform the normal variables back into the original distribution by applying an inverse integral transform;

8. Disaggregate data into hourly resolution to capture the variability of the sources once monthly/weekly inflow and renewable scenarios have already been forecasted. This step consists in applying a Principal Components Analysis (PCA) decomposition in each month/week of the aggregated historical data, resulting in a decomposition matrix for each month/week to be applied in the generated scenarios.

The process starts (step 1) with the inflow forecast and Monte-Carlo simulation that generates a total of $|\mathcal{S}|$ scenarios. Steps 2 and 3 are than used to estimate the renewable generation distribution function from the historical data and convert (map) it to a Gaussian form, as mandatory when working with Bayesian networks. In steps 4-6, a Bayesian network is applied for each renewable site. This means that, for each renewable, a regression model is fitted after testing all possible combinations between inflows and other renewable sites as explanatory variables and selecting the significant ones. Step 7 is than used to restore the original distribution function, using the mapping from step 3. Finally, in step 8, the forecasted renewable generation is disaggregated into hourly time steps using the historical data to infer the profiles. Note that by the end of this process, there will be a set of $|\mathcal{S}|$ renewable generation scenarios. 


\subsection{2}

\section{Market Simulation}

As noted by [36], renewable generation is a fundamental aspect of electricity spot prices in markets with high levels of penetration. Thus, to capture essential characteristics of the price volatility increase brought by intermittent sources, we employ the official SDDP [27] methodology used in Brazil (and other hydro-dominated countries), considering a highly renewable expansion plan proposed by experts (refer to Section 2.1). The SDDP simulates the optimal operation of hydros and thermoelectric units as a function of simulated scenarios of demand and renewable injections. Another output is the marginal operational cost, which is proxy for spot prices. The SDDP run also returns a set of coherently and independently generated scenarios (following a Monte-Carlo approach) containing spot prices and renewable units' generation. For an interested reader, we refer to [37] for further details.

\subsection{3}

\section{Impacts of Short-term Uncertainties in Revenue}

Figure 3.1 shows hourly output profiles of solar and wind plants in the Northeastern area of Brazil. In this example, both plants produce, on average, 2.4 GWh in one day (or 100 avgMW), and have their output concentrated during the mornings and afternoons (6AM - 6PM).

Moreover, three spot profiles are illustrated in red, all with a daily average of $150 \mathrm{R} \$ / \mathrm{MWh}$. The flat curve represents a situation where spot prices are not hourly defined. The dotted curve, on the other hand, exhibits the spot price (generated using SDDP) for a low renewable penetration scenario, in which prices tend to increase in peak load hours. Finally, the dashed curve represents a high renewable penetration setting (object of this study), and clearly shows a price drop during the day. This phenomenon is caused by the over-generation of solar energy when the sun is shining, which decreases the net demand during these hours, originating a profile known as "duck curve", which is already observed in systems such as California's.

Table 3.1 shows the impact of each spot price profile to the daily spot clearing of a solar and a wind producer that have a 100 avgMW flat energy delivery commitment. Naturally, the flat profile has a null correlation factor to the plant's production and, therefore, does not result in daily gains or expenses in the spot market. In the low renewable penetration setting, positive correlation between production and prices is demonstrated for both wind and solar units. This means that production tends to be higher when prices are high, which leads to gains in the spot market. Nevertheless, at the high 


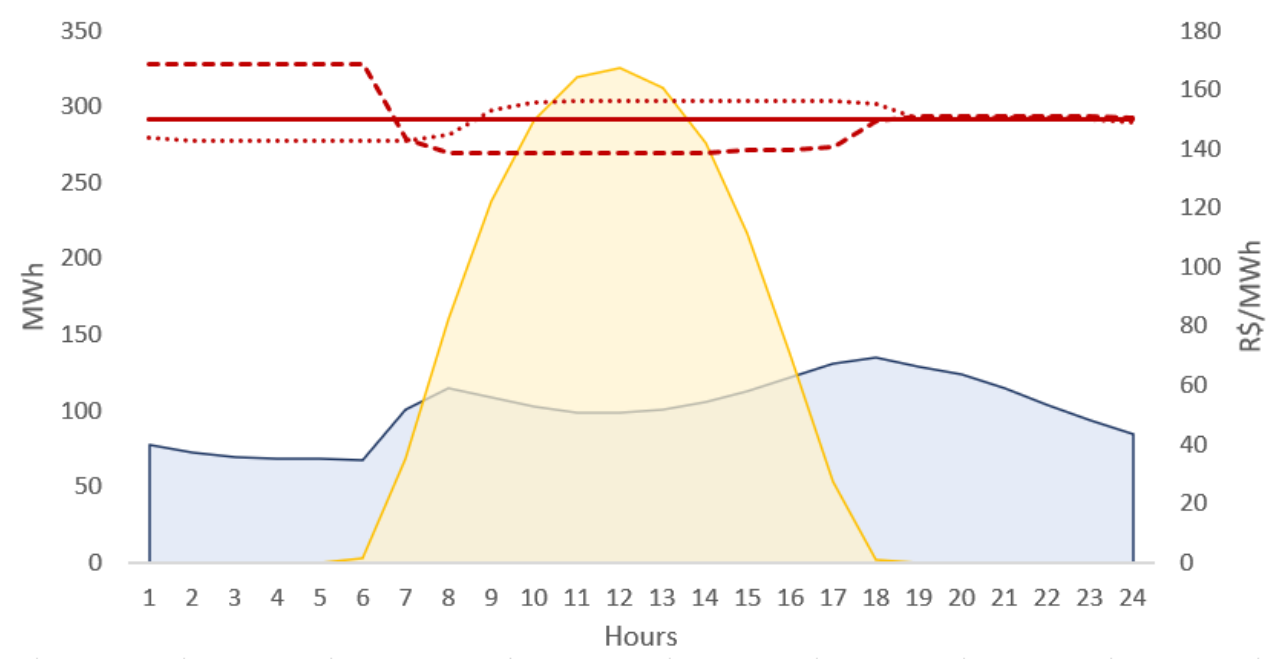

Figure 3.1: Hourly spot price and generation profiles.

Table 3.1: Impact of spot price and renewable production correlation in daily spot clearing

\begin{tabular}{|c|c|c|c|c|c|c|}
\hline & \multicolumn{6}{|c|}{ Prices } \\
\hline & \multicolumn{2}{|r|}{ Flat } & \multicolumn{2}{|c|}{ Low Renewable } & \multicolumn{2}{|c|}{ High Renewable } \\
\hline & $\begin{array}{l}\text { Corr. } \\
\text { factor }\end{array}$ & $\begin{array}{c}\text { Daily spot } \\
\text { clearing } \\
(\mathrm{kR} \$)\end{array}$ & $\begin{array}{l}\text { Corr. } \\
\text { factor }\end{array}$ & $\begin{array}{c}\text { Daily spot } \\
\text { clearing } \\
\quad(k R \$)\end{array}$ & $\begin{array}{l}\text { Corr. } \\
\text { factor }\end{array}$ & $\begin{array}{c}\text { Daily spot } \\
\text { clearing } \\
(\mathrm{kR} \$)\end{array}$ \\
\hline Wind & 0.00 & 0.00 & 0.68 & 1.82 & -0.72 & -4.22 \\
\hline Solar & 0.00 & 0.00 & 0.67 & 10.99 & -0.74 & -26.36 \\
\hline
\end{tabular}

renewable penetration setting, the correlation factor is negative. This means that the generator would have to purchase energy in the spot market when prices are high to comply with his contractual obligations. Conversely, excess energy selling would occur when prices are low, leading to negative daily spot clearings.

\section{2}

\section{Long-term Uncertainties}

Trading decisions are by no means static. As time goes on and new information becomes available, decisions that were made in the past can be reassessed, or previously postponed decisions can, finally, be made. Thus, when evaluating a trading strategy, it is very important to consider this timing flexibility. The more uncertain the future is, the more valuable this flexibility becomes. For instance, if a trading company has to buy a certain volume of 
power, the energy portfolio manager has essentially two options: (i) either purchase the required energy today at current market prices or (ii) postpone the purchase to a future date (see Figure 3.2).
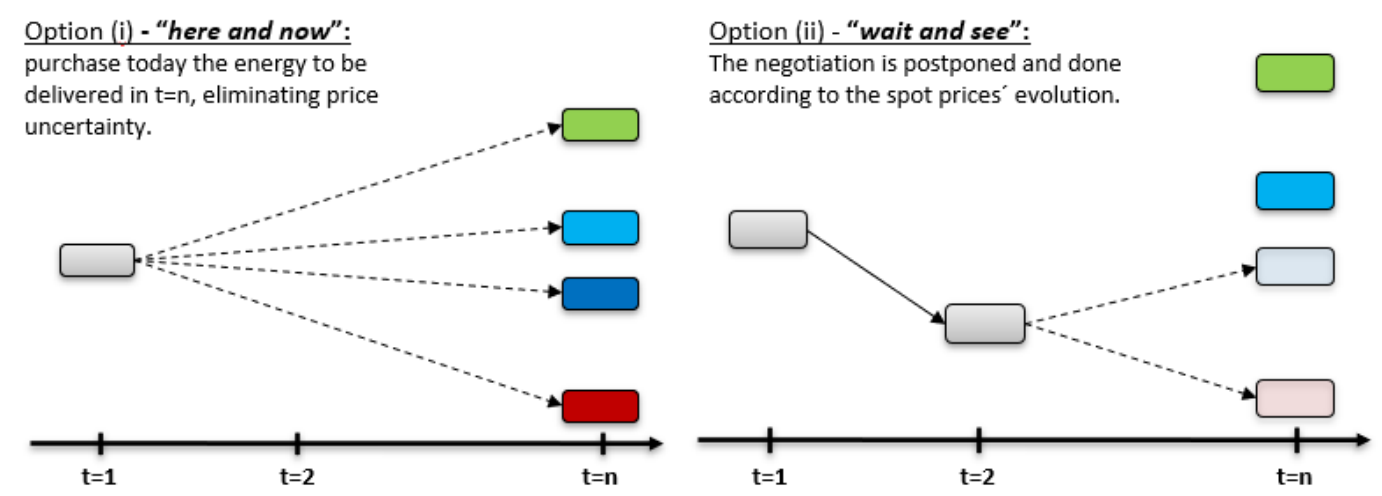

Figure 3.2: "Here and now" versus "wait and see" strategies.

The optimal decision will depend on the expected evolution of power prices and on the manager's risk aversion profile. On one hand, the "wait-andsee" strategy allows the manager to have more information before locking in a price. On the other hand, the actual final price may end up being higher than it would have been if the manager had previously bought the energy. Therefore, it's very important to weigh the risks against the benefits when timing the decision. In situations like these, a common approach in the stochastic framework is to model the outcome uncertainty through a decision tree $[11,15,16,22,38]$. Other approaches such as price lattices [9] and Markov chains are also found in literature [39].

\subsection{1}

\section{Impacts of Long-term Uncertainties in Revenue}

Suppose that a trading company needs to buy energy for the following month. It has searched the market for supply contracts, and has found that the available options are:

1. Sign a contract today locking in a price of $215 \mathrm{R} \$ / \mathrm{MWh}$.

2. Wait a little longer to go after a supply contract.

Since it is not possible to know in advance how market prices will be like in the future, if the manager chooses the second option there is a real possibility that power prices will rise and that he will end up spending more than he would have if he were to sign the supply contract today, for $215 \mathrm{R} \$ / \mathrm{MWh}$. On the 
other hand, it's also possible that prices may fall, and that he will end up paying less.

In order to evaluate both possibilities, the manager decides to build a decision tree to represent price evolutions between today and the following month in three distinct and equiprobable categories: high, medium and low. A crucial point when building the tree is the estimation of prices at each node, i.e., what would be the contract prices for each possible path realization.

Let's suppose, in this example, that the manager estimates that:

- Depending on "bad" weather conditions (low radiation, wind speed or hydrology), prices can rise up to $25 \%$;

- On average, prices will fall slightly by $7 \%$;

- If weather conditions are good, then prices will fall by $32 \%$.

Hence, the manager has to decide between signing a contract today, for $215 \mathrm{R} \$ / \mathrm{MWh}$; or waiting and finding prices of $\{268,200,146\} \mathrm{R} \$ / \mathrm{MWh}$. Assuming that the manager is risk neutral and that his objective is to minimize the energy acquisition cost's expected value, then the optimal decision is to wait to purchase the energy:

$$
\mathbb{E}[\text { wait }]=268 \frac{1}{3}+200 \frac{1}{3}+146 \frac{1}{3}=204.87 R \$
$$

Note that the expected value of strategy 2 is lower than the expected value of strategy 1 (buy for $215 \mathrm{R} \$$ in advance). Thus, he would choose to wait to sign a supply contract.

\section{3}

\section{Combining Uncertainties: a Proposed Framework}

In this section we propose a framework in which the correlations between inflow forecasts, renewable generation, spot and contract prices are accounted for by means of interconnected long- and short-term decision trees.

\subsection{1}

\section{Multi-scale Scenario Tree}

As opposed to the previously reported approaches, in this work the scenario tree structure is built to preserve all original independently generated (random) scenarios of spot prices and renewable generation from Section 3.1. This is done to characterize intra-stage short-term uncertainty. In this subsection we describe the procedure to obtain a dual scale scenario tree 
structure (with hourly and weekly uncertainties), similar to the one in [22], that allows accounting for both strategic and operational levels.

The following basic definitions are used in this article for the specification of a scenario tree topology:

- Scenarios: comprise possible time-dependent realizations for the shortterm uncertain parameters. Their values are obtained under the assumptions of Section 3.1 and depicted in Figure 3.3 as dashed blue wavy time series. Mathematically, they are represented by $s \in \mathcal{S}$.

- Nodes: represent a moment in time and level of conditional information in which a contracting (strategic) decision can be made (except the leaves). They are also referred to as clusters, or system states, and are depicted in Figure 3.3 as gray rectangles. They are obtained through a spot-price-based clusterization process of the scenarios applied in each stage according to the steps provided below in this Section. Additionally, in each node conditional values for forward prices are obtained following the procedure described in Section 3.3.2. Mathematically, they are represented by $n \in \mathcal{N}$ and contain a set of scenarios $\mathcal{S}_{n}$.

- Paths: represent the information-revelation process characterized by a filtration of the scenarios through time. This filtration is defined by the clusterization process describing how child nodes are obtained, thereby representing the structure of the tree. Paths are represented by the thick black lines connecting nodes in Figure 3.3. Mathematically, each path is characterized by the set of scenarios $\mathcal{S}_{n}$ in a given leaf node $n \in \mathcal{L}$. Note that $\mathcal{L}$ is the subset of nodes $\mathcal{N}_{T} \subset \mathcal{N}$ associated to the leaves.

The scenario tree used in this work is generated for a finite planning horizon over $t=1, \ldots, T$ stages with weekly time steps. Each node contains information of generating units' outputs and spot prices in hourly resolution for the whole week, as well as weekly forward prices for all contracts.

Once a large number of scenarios $\mathcal{S}$ is simulated, a clusterization algorithm (i.e., K-means [40] or quicksort) is used to split scenarios into $k$ subsets that share similarities for each stage. In this work we use weekly average spot prices as the similarity metric. The split of the scenarios in the nodes that form our scenario tree is presented in the following Algorithm:

The proposed Algorithm 1 does not require the translation of grouped scenarios into a single pivot scenario (e.g. obtained through the average or other scenario reduction techniques $[39,41])$, but considers the scenario's probability distribution function at each node. Therefore, even though scenarios are grouped to form tree paths, the full set of simulated scenarios $\mathcal{S}$ will still be 


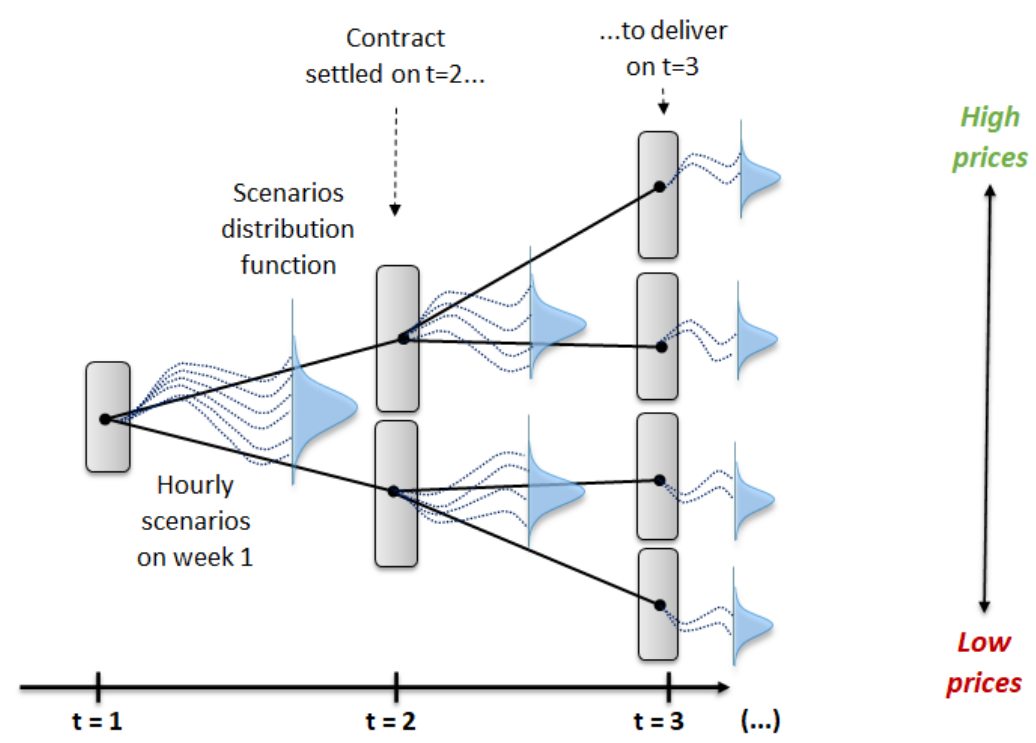

Figure 3.3: Tree paths and scenario distributions by cluster (node).

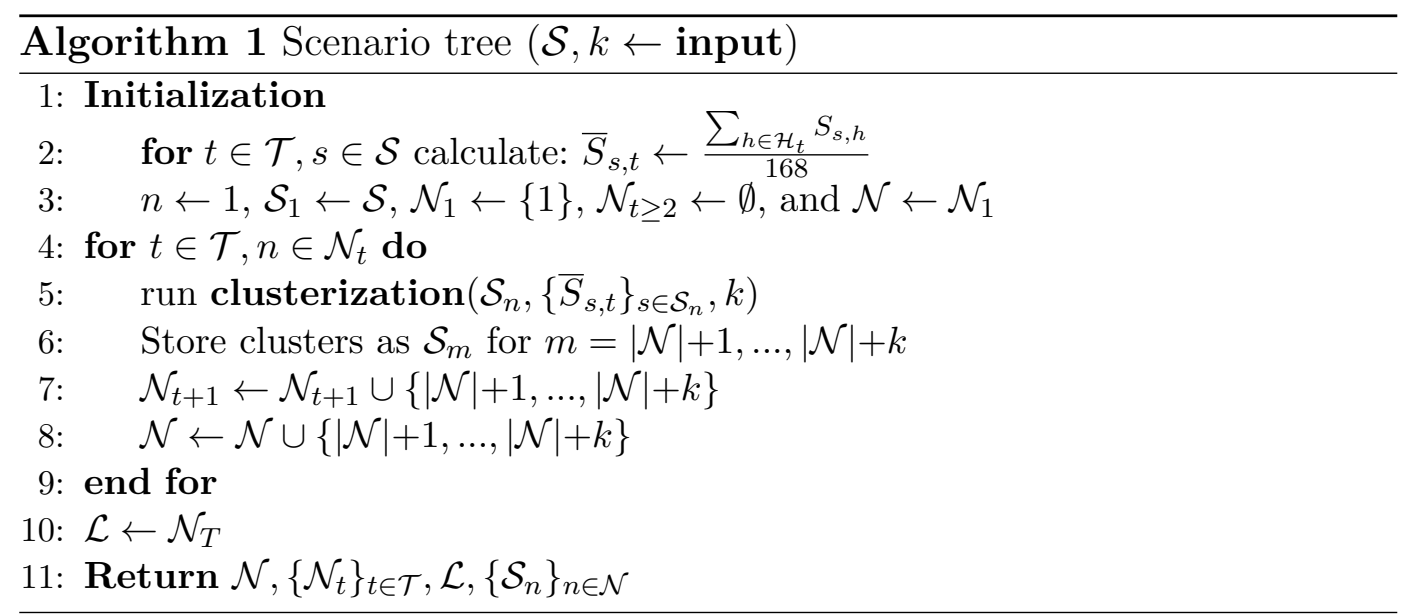

considered, which means that there will be no loss of information. Hence, this approach maintains the statistical properties of both strategic and operational uncertainty data sets and ensures that all extreme scenarios are analyzed, which is essential in risk analysis.

\subsection{2}

\section{Forward Prices}

Contracts are the basis of the agents' strategy in the electricity market for both the sales (generators) and the purchase (consumers and traders) segments.

In our model, forward contracts are defined by three main parameters, namely: the negotiation (decision) stage, $\tau_{c}$, and the initial, $\tau_{c}^{\text {start }}$, and final, $\tau_{c}^{e n d}$, stages of the delivery period ${ }^{1}$. Considering the tree structure in Figure 3.3,

\footnotetext{
${ }^{1}$ Note that in practice, a given product, e.g., forward contract with a given initial and final
} 
for contracts negotiated in $t=\tau_{c}=1$, prices are specified for a single node. On the other hand, contracts with parameter $\tau_{c}=2$ exhibit two different prices, as there are two nodes in the negotiation stage.

Conventional forward pricing approaches consider two key components: spot price expectations and risk premiums [42-44], which can be expressed by

$$
F_{t}=\mathbb{E}\left[S_{s, \tau} \mid \operatorname{Info}_{t}\right]+\Delta_{t}
$$

for the delivery period $\tau$ of the forward. The latter component characterizes the bias due to liquidity and agents' risk aversions in the market. Since prices in our model are defined for each node of the scenario tree, the first price component is obtained through the expected spot prices foreseen strictly on the scenarios contained in that node, i.e, according to:

$$
\mathbb{E}\left[S_{s, t} \mid \mathcal{S}_{n}\right]=\sum_{s \in \mathcal{S}_{n}} \frac{P_{s}}{\sum_{s^{\prime} \in \mathcal{S}_{n}} P_{s^{\prime}}} S_{s, t} \forall n \in \mathcal{N}
$$

The total contract price $F_{c, n}$ is then given by (3-2) plus an exogenously determined $\Delta_{t}$. In our study, we calculated risk premiums using a simple linear regression of historical forwards and spot prices [45].

delivery period, can be negotiated at different periods by different prices. To consider this possibility in our model, we assume different contracts with the same initial and final delivery periods for each possible negotiation stage, each of which considering the correspondent forward price. 


\section{Risk Aversion}

\section{1}

\section{Characterizing Risks}

Even though agents aim to maximize expected revenue, most of the generators and retailers are risk averse. This means that decisions that involve a high level of risk may not be acceptable even if their expected return is higher than it would be with other options.

Although it is extremely common to assume risk and uncertainty synonymously, there is a significant difference between the two definitions. More specifically, risks are consequences of uncertainties. While the latter refers to situations of limited knowledge, in which it is not possible to determine with certainty the future value of one or more quantities, the former comes from an uncertainty circumstance that can lead to undesirable results.

In chapter 3 short- and long-term uncertainties are characterized as the lack of knowledge in future spot prices, generation, and derivative prices. Hence, risks are seen in situations of extreme market prices and plant outputs that result in low or negative outcomes.

Among the intrinsic risks to the energy trading activity, we highlight:

- Market risks: include price-volume risks and are consequences of price and production uncertainty and volatility.

- Operational risks: associated with uncertainties in equipment availability, fuel availability, etc.

- Regulatory risks: associated with changes in regulation that may cause financial losses.

- Credit risks: caused by counterparty defaults.

Note that we are able to capture the sensitivity to weather variability and operational uncertainties by simulating extreme production scenarios, similar to what is done in [46]. Furthermore, by applying financial risk constraints to the problem it is possible to prevent market risks. As for the regulatory and credit risks, they are hardly quantifiable and therefore are not considered at the moment. 


\section{2}

\section{Risk Measures}

A risk measure is a function that associates a given random variable (e.g. profit) with a real number characterizing the risk. As previously mentioned, profit scenarios forecasting is intended to assist decision making in order to avoid significant losses, having great importance in the management of personal and company risk. In this context, the probability and extent of losses should be estimated in two steps: (i) modeling of the distribution of future profits and losses (i.e., future returns from portfolios or assets) and the (ii) measuring of the financial risks associated to this distribution.

The most commonly used risk measures in the electricity market are defined and formulated in [4], namely:

1. Variance/mean-variance

2. Shortfall probability

3. Downside risk

4. Value-at-Risk (VaR)

5. Conditional-Value-at-Risk (CVaR)

The variance measure was firstly proposed in risk management problems by the notorious work of Markowitz [3]. This is a statistical measurement that determines the degree of variability (dispersion) from the average or mean of a random variable. Therefore, a large variance indicates a high risk of experiencing revenues far from the expected one, regardless of whether they represent positive or negative deviations. Nevertheless, an agent is usually worried about low profit scenarios, while positive deviations from the expected value are actually desirable.

As a solution to overcome the drawbacks of equally penalizing high and low profit scenarios other measures were introduced.

The shortfall probability is a linear measure that characterizes risk as the probability of the profit being smaller of a given pre-fixed target value $\kappa$. Likewise, the downside risk quantifies the expected value of the profit being below that target. Even though these are defined by [4] as easily implementable, they are not coherent risk measures, which means that they do not fulfill at least one of the four desirable properties presented by Artzner et al. in [47], them being:

1. Translation invariance:

$$
\rho(X+c)=\rho(X)-c
$$


Interpretation: adding a risk free asset $c$ to a portfolio with risky assets $\mathrm{X}$ reduces risk by the same amount.

2. Subadditivity:

$$
\rho(X+Y) \leq \rho(X)+\rho(Y)
$$

Interpretation: The portfolio risk should be less or equal to the risk of its individual components. In other words, the risk measure should not penalize diversification.

3. Positive homogeneity:

$$
\rho(k X)=k X
$$

Interpretation: If an asset $\mathrm{X}$ is linearly increased or decreased, the resulting risk will also be, by the same factor $k$.

4. Monotonicity:

$$
\text { if } X \leq Y, \rho(X) \geq \rho(Y)
$$

Interpretation: If an asset $\mathrm{Y}$ dominates an asset $\mathrm{X}, \mathrm{Y}$ is less risky.

Similarly to the shortfall probability, the Value-at-Risk accounts for risks according to a pre-fixed threshold value. However, instead of choosing a cutoff outcome, the threshold is defined by a quantile of the random variable distribution, $(1-\alpha) 100 \%$. For instance, if $\alpha$ is equal to $95 \%$, it means that there is a $95 \%$ chance in obtaining an outcome that is higher or equal to the $\mathrm{VaR}$ value. Note that both of these measures are blind to fat tails beyond the values of $\kappa$ or VaR. Moreover, the problem of non-coherence persists in the VaR metric, as it does not meet the subadditivity property (except in cases of elliptically distributed outcomes).

Finally, the Conditional Value-at-Risk, calculated as the average of the $(1-\alpha) 100 \%$ worst scenarios, was suggested as a coherent alternative to the VaR. This makes the CVaR one of the main and most promising risk metrics to be used in stochastic programming, as its convex function - resulting from the combination of subadditivity and positive homogeneity notions - can be condensed into a simple linear programming formula proposed by Rockafellar and Uryasev in [24]. Additionally, it can be seen from Figure 4.1 that the CVaR overcomes VaR limitations by indicating, in a more appropriate way, the potential of losses that exceed the confidence interval $(1-\alpha) 100 \%$, defined when calculating the average of losses that exceed the VaR value. 


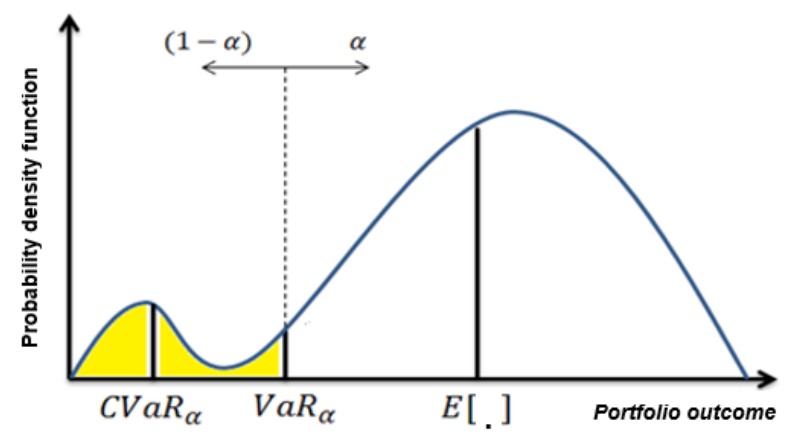

Figure 4.1: VaR and CVaR risk metrics applied to illustrative outcome density function.

\section{3}

\section{Time-consistency in Risk Averse Dynamic Stochastic Programming}

According to [12], strategies are time consistent if the future planned decisions continue to be optimal as the world evolves to one of the predicted paths. Therefore, "at every system state, optimal decisions should not depend on scenarios which we already know cannot happen in the future." Even though this may seem like a straightforward concept, many risk constrained approaches widely used in stochastic optimization, such as the maximization of CVaR, can lose time consistency once dynamic decisions are introduced.

In [13], a practical example of a time inconsistent policy is given. In such case, an investor wants to maximize the risk-return trade-off of a dynamic two-asset allocation problem. To do so, he uses a decision tree approach and constructs a linear stochastic programming problem that maximizes the equally weighted convex combination between the average return and the CVaR.

The first asset considered by the agent, indexed by $i=1$, is risk free and its return assumes a null value at every system state, i.e, $F_{1, s, t}=$ $0 \forall s \in \mathcal{S}=\{1,2,3,4\}, \forall t \in \mathcal{T}=\{1,2\}$. The second one is assumed to have independent and identically distributed returns according to the graphic representation in Figure 4.2.

Once the optimization problem is solved using $\alpha=75 \%$, the following asset allocation solution $x_{i, s, t} \forall i \in\{1,2\}, s \in \mathcal{S}, t \in \mathcal{T}$ is obtained, in percentage values of the total investment: 


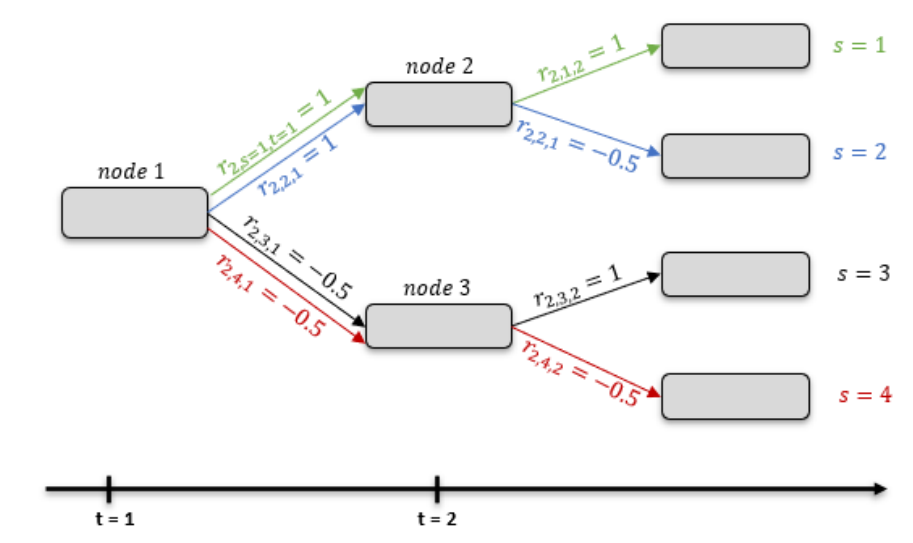

Figure 4.2: Return tree for asset 2.

$$
x_{1, s, t}=\left\{\begin{array}{ll}
50 \%, & \forall t=1, s \in \mathcal{S} \\
0 \%, & \forall t=2, s \in\{1,2\} \\
100 \%, & \forall t=2, s \in\{3,4\}
\end{array} \quad x_{2, s, t}= \begin{cases}50 \%, & \forall t=1, s \in \mathcal{S} \\
100 \%, & \forall t=2, s \in\{1,2\} \\
0 \%, & \forall t=2, s \in\{3,4\}\end{cases}\right.
$$

At node 1 , it is optimal to invest equally in assets 1 and 2 , while at node 2, the full investment should be made in the risky asset. Finally, at node 3, the model suggests to invest solely in the risk free one. Notwithstanding, the authors aim to prove that the optimal solution would have been different if the world actually evolved to node 2 . In other words, at node 1 the future planned decisions for node 2 are different from the ones that are actually going to be implemented.

In fact, the optimal solution obtained when the first stage problem is run from node 2 , foreseeing strictly paths 1 and 2 , is to invest everything in the risky asset. This happens because, from $t=1$, the $75 \%$-CVaR relies in scenario 4. Then, at node 2 , it is optimal to choose the investment strategy with the highest expected return since this decision will not affect the terminal wealth at scenario 4 . This example shows that a risk-averse time inconsistent policy may lead to risk neutral decisions at intermediate system states.

Moreover, when the problem is run using the time consistent model proposed in the article, the first stage decision at node 1 changes to indicate the full investment in the risk free asset. Note that this strategy is more conservative compared to the time inconsistent one, since it considers risk at every system state. 


\section{4}

\section{Risk Policy Modeling: A Proposed Framework}

Having addressed the problem of temporal consistency in risk-averse dynamic programming, this work proposes three different time-consistent risk constraints established by user-defined limits and directly compatible with the decision tree approach:

1. Stage-wise $\alpha-C V a R$

2. Monthly aggregated $\alpha-C V a R$

3. One-period drawdown

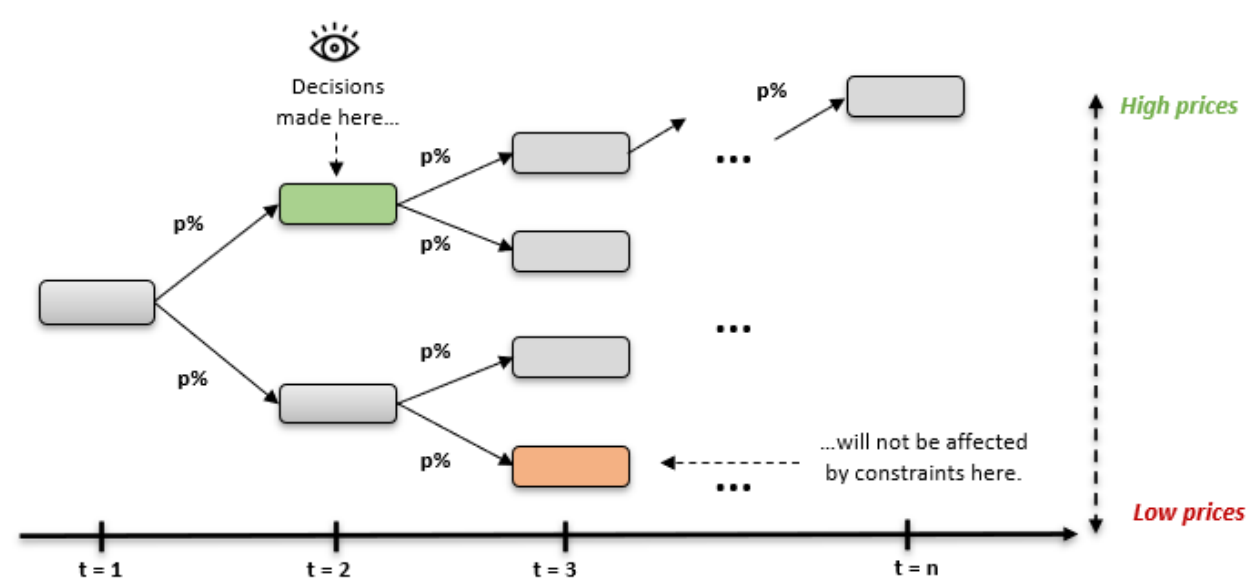

Figure 4.3: Time-consistent risk constraints.

Constraint (1) can be interpreted minimum revenue allowed by stage (week) and estimated as an average of the $\alpha \%$ worst-case revenue scenarios in each tree path. This constraint is very common in stochastic problems, however, it can easily lose time consistency when applied in dynamic programming. Note that, if the $\alpha-C V a R$ is calculated based on the full set of scenarios $S$ by stage, decisions in a specific system state could be affected by extreme scenarios in an opposite state and path.

However, if the constraint is applied not only to every stage, but to the probability distribution of scenarios contained at each system state $n$, time consistency is guaranteed in the analysis. In this case, as each node contains only a subset of scenarios $S_{n}$, excluding the ones that are already known not to happen in the future, future planned decisions will continue to be optimal as the world evolves. For instance, suppose the market follows in a high price 
path in $t=2$. In this setting, decisions made in this stage will not be affected by limits at any future state of the low price trajectory.

The same logic can be extended to the monthly aggregated $\alpha-C V a R$ constraint, which is similar to (1), but considers the present value of the full horizon (month) per path of the tree. In such case, the number of constraints will depend in the number of trajectories (or leaf nodes). Furthermore, it is ensured that regardless of the tree path the agent faces in the future, there will be only an $(1-\alpha) 100 \%$ chance, or less, of an outcome under the constraint limit.

Finally, the maximum one-period drawdown can be interpreted as the maximum shortfall allowed between stages, and is used to reduce revenue volatility. Although it is not very recurrent in the electricity trading literature, in practical life it is one of the most widely quoted measures within the universe of hedge funds and commodity trading advisors [48]. Moreover, while it fails to satisfy the translation invariance and monotonicity axioms, it is a convex function, which allows for a linear programming representation. Unlike the others, this constraint already has a "time consistent nature", as it is applied to each independent scenario.

These are sound and intuitive risk policies, as they preclude abrupt shortfalls, not only in an aggregate manner, but stage- and interstage-wise, which is crucial to maintain companies' cash flow stability and avoid bankruptcy. 


\section{5}

\section{Portfolio Optimization Problem}

The proposed model is cast as a multistage stochastic linear program, driven by the maximization of the expected agent revenue and subject to timeconsistent risk constraints as follows:

$$
\underset{\begin{array}{c}
x_{c, n}, r_{s, t}, e_{s, t}^{l g}, e_{s, t}^{s h} \\
z_{n}^{w}, z_{n}^{l}, s_{s, t}, s_{s}^{l,}
\end{array}}{\operatorname{Maximize}} \sum_{t \in \mathcal{T}} \sum_{s \in \mathcal{S}} P_{s} r_{s, t}
$$

Subject to bounds and revenue constraints:

$$
\begin{aligned}
& 0 \leq x_{c, n} \leq 1 \\
& r_{s, t}=\sum_{h \in \mathcal{H}_{t}}\left[\sum_{i \in \mathcal{U}} G_{i, s, h}+\sum_{c \in C^{b u y}} x_{c, n\left(s, \tau_{c}\right)} Q_{c, h}\right. \\
& \left.-\sum_{c \in C^{\text {sell }}} x_{c, n\left(s, \tau_{c}\right)} Q_{c, h}\right] S_{s, h} \\
& +\sum_{c \in C^{\text {sell }}} x_{c, n\left(s, \tau_{c}\right)} F_{c, n\left(s, \tau_{c}\right)} \sum_{h \in \mathcal{H}_{t}} Q_{c, h} \\
& -\sum_{c \in C^{\text {buy }}} x_{c, n\left(s, \tau_{c}\right)} F_{c, n\left(s, \tau_{c}\right)} \sum_{h \in \mathcal{H}_{t}} Q_{c, h}-\sum_{i \in \mathcal{U}} \sum_{h \in \mathcal{H}_{t}} G_{i, s, h} C_{i}
\end{aligned}
$$

$$
\forall s \in \mathcal{S}, \forall t \in \mathcal{T}
$$

Prevent short selling:

$$
\begin{array}{rlrl}
e_{s, t}^{l g} & =\sum_{h \in \mathcal{H}_{t}} \sum_{i \in \mathcal{U}} E_{i, h}+\sum_{c \in C^{b u y}} x_{c, n\left(s, \tau_{c}\right)} \sum_{h \in \mathcal{H}_{t}} Q_{c, h} & & \forall s \in \mathcal{S}, \forall t \in \mathcal{T} \\
e_{s, t}^{s h}=\sum_{c \in C^{\text {sell }}} x_{c, n\left(s, \tau_{c}\right)} \sum_{h \in \mathcal{H}_{t}} Q_{c, h} & \forall s \in \mathcal{S}, \forall t \in \mathcal{T} \\
e_{s, t}^{l g}-e_{s, t}^{s h} \geq 0 & \forall s \in \mathcal{S}, \forall t \in \mathcal{T}
\end{array}
$$

Risk constraints:

i. Stage-wise weekly CVaR (W CVaR)

$$
\begin{array}{lrl}
\delta_{s, t}^{w} \geq 0 & \forall s \in \mathcal{S}, \forall t \in \mathcal{T} \\
z_{n}^{w}-\frac{1}{1-\alpha} \sum_{s \in S_{n}} \frac{P_{s}}{\sum_{s^{\prime} \in S_{n}} P_{s^{\prime}}} \delta_{s, t_{n}} \geq R_{\text {min }}^{w}: \lambda_{n} & \forall n \in \mathcal{N} \\
\delta_{s, t}^{w} \geq z_{n(s, t)}^{w}-r_{s, t} & \forall s \in \mathcal{S}, \forall t \in \mathcal{T}
\end{array}
$$


ii. Monthly aggregated CVaR (M CVaR)

$$
\begin{array}{ll}
\delta_{s}^{l} \geq 0 & \forall s \in \mathcal{S} \\
z_{n}^{l}-\frac{1}{1-\alpha} \sum_{s \in S_{n}} \frac{P_{s}}{\sum_{s^{\prime} \in S_{n}} P_{s^{\prime}}} \delta_{s}^{l} \geq R_{\text {min }}^{l}: \gamma_{n} & \forall n \in \mathcal{L} \\
\delta_{s}^{l} \geq z_{n(s, T)}^{l}-\sum_{t \in \mathcal{T}} r_{s, t} & \forall s \in \mathcal{S}
\end{array}
$$

iii. One-period maximum drawdown

$$
r_{s, t-1}-r_{s, t} \leq \theta: \eta_{s, t} \quad \forall s \in \mathcal{S}, \forall t \in\{2 . . T\}
$$

The objective function (5-1) maximizes the agent's average income over the month. Constraint (5-2) sets the decision variable that defines the share $x_{c, n}$ of each contract $c$. Note that this variable is set exclusively for nodes in the settlement stage $\tau_{c}$ of the respective contract. Therefore, for each node of the tree, each contract has a single decision variable $x_{c, n}$ that applies to all scenarios passing through that node. This ensures non-antecipative decisions.

In (5-3), the agent's net revenue $r_{s, t}$ is determined by the sum of the wholesales market settlement plus fixed revenue of selling contracts, minus the costs of buying contracts and generating units. Purchases and sales in the wholesales market depend on the shortage and excess of energy in each scenario $s \in S$ and hour $h \in \mathcal{H}$. In other words, if the total generation and purchased contract amounts are greater than the total amount sold through contracts, this excess is cleared in the spot market. Likewise, energy shortages are cleared as purchases in the spot market. It is worth highlighting that even though contract decisions are made per node, i.e., enforced for all scenarios in $S_{n}$, revenues are computed for each scenario. In this context, the statistical properties (and extreme scenarios characterization) of the original data set are preserved.

Because we assume that the trading company uses forward contracts for hedging purposes and not for speculation, constraints (5-4)-(5-6) prevent short selling, i.e., the total generating units' firm energy certificates and contract purchases must be greater or equal to the total energy sold through contracts.

Finally, constraints (5-7)-(5-13) emulate the agent's risk profile through financial limits. Using Rockafeller's linear formulation for the CVaR applied to the revenues (see [5]), constraint (5-9) (and the non-negative bounds (5-7)) makes $\delta_{s, t}^{w}$ to play the role of positive piecewise-linear truncation function. In this context, according to [24], in the optimal solution, $z_{n}^{w}$ represents the $(1-\alpha)$-quantile of the net revenue in each node. Note that the $\alpha-C V a R$ 
constraint (5-8) is adapted to the filtration process induced by the tree structure. Thus, this risk constraint is calculated based on the conditional probability distribution formed by the subset of scenarios $\mathcal{S}_{n}$ at each node. In this context, this constraint is limiting the conditional average of the $(1-\alpha) 100 \%$ worst scenarios to be greater or equal to $R_{\min }^{w}$ for every node of the tree. Constraints (5-10)-(5-12) follow the exact same logic, but are extended to the accumulated net revenue ( sum of $r_{s, t}$ ) at each leaf node. In this case, $(5-11)$ is limiting the average of the $(1-\alpha) 100 \%$ worst scenarios to be greater or equal to $R_{\text {min }}^{l}$ for every path in the tree. Therefore, regardless of the path the agent faces, there will be only an $(1-\alpha) 100 \%$ chance, or less, of observing a net revenue lower than $R_{\text {min }}^{l}$. Note that $R_{m i n}^{w}$ and $R_{\text {min }}^{l}$ can also be defined by node or leaf, to represent risk control policies with dynamic limits. Nevertheless, for the sake of simplicity, we have chosen to represent fixed limits. Finally, the maximum one-period drawdown is limited by $\theta$ in constraint (5-13). 


\section{6 \\ Performance Measure}

\section{1 \\ Motivation}

In a real-life situation, a trader may be confronted with a variety of strategy possibilities, that do not necessarily comply with the company's risk policy, generally defined by a set of risk constraints. In this setting, such company may wish to assess the value of a given strategy or portfolio according to its risk policy. Although this can be a simple task under expected utility framework or when optimizing CVaR-based metrics in the objective function (see [49] for a theoretical example linking CVaR and certainty equivalents, [13] for the multistage case where nested CVaR metrics are used, and for [7] and [8] for recent applications), it is not trivial when CVaR constraints are considered. Nevertheless, once financial limits are imposed, it is worth extracting a correspondent preference functional compatible with the optimization problem used to select the best contracting strategy.

The definition of such a metric allows evaluating different solutions, e.g., obtained with other models and thereby possibly not attending to the agent's risk limits, under a single viewpoint consistent with the preference induced by the optimization-based decision model. To this matter, the measure must receive a given stochastic stream flow, parameterized by a given set of contracting decisions, and be representative of the following key aspects of the optimization problem: i) the degree of infeasibility and ii) the performance in terms of objective function. In this case, for instance, portfolios with higher expected incomes and the same degree of infeasibility should be preferable to those with worse expected incomes. Additionally, the preference functional should give more value to the portfolio selected as optimal by its underlying optimization problem, i.e., the preference of the optimal portfolio must be maximal among all possible portfolios. 


\section{2}

\section{Preference Functional}

To formalize the process of obtaining such a functional, the maximum revenue problem with stage-wise risk constraints is described in a compact manner as follows:

$$
\underset{\mathbf{x}}{\operatorname{Maximize}} \sum_{t \in \mathcal{T}} \mathbb{E}\left[r_{t}\left(\mathbf{x}, \boldsymbol{\xi}_{s, t}\right)\right]
$$

subject to:

$$
\begin{array}{lr}
A \mathbf{x}_{n} \leq b & \forall n \in \mathcal{N} \\
\rho\left[r_{t}\left(\mathbf{x}, \boldsymbol{\xi}_{s, t}\right) \mid \mathcal{S}_{n}\right] \geq R_{\text {min }}^{w} \quad: \pi_{n} & \forall t \in \mathcal{T}, n \in \mathcal{N}_{t} .
\end{array}
$$

In the compact formulation, constraints (5-2)-(5-6) from the original problem are represented by (6-2). The stage-wise CVaR constraints in (5-7)(5-9) are denoted as (6-3). For the sake of simplicity and didactic purposes, we omit the other two sets of risk constraints (5-10)-(5-13) in the compact formulation. Notwithstanding, as the developments carried out in this section apply to any set of linear constraints, the extension of these results to consider constraints (5-10)-(5-13) are straightforward. Thus, we can write the following penalized problem, conveniently considering an exact penalization for the risk constraint (6-3):

$$
\underset{\mathbf{x}, \nu}{\operatorname{Maximize}} \sum_{t \in \mathcal{T}} \mathbb{E}\left[r_{t}\left(\mathbf{x}, \boldsymbol{\xi}_{s, t}\right)\right]-\sum_{n \in \mathcal{N}} \lambda_{n} \nu_{n}
$$

subject to:

$$
\begin{array}{lr}
A \mathbf{x} \leq b & \forall n \in \mathcal{N} \\
\nu_{n} \geq 0 & \forall n \in \mathcal{N} \\
\rho\left[r_{t}\left(\mathbf{x}, \boldsymbol{\xi}_{s, t}\right) \mid \mathcal{S}_{n}\right]+\nu_{n} \geq R_{\text {min }}^{w} & \forall t \in \mathcal{T}, n \in \mathcal{N}_{t}
\end{array}
$$

whose objective function can be read as

$$
\phi(\mathbf{x}, \boldsymbol{\lambda})=\sum_{t \in \mathcal{T}}\left[\mathbb{E}\left[r_{t}\left(\mathbf{x}, \boldsymbol{\xi}_{s, t}\right)\right]-\sum_{n \in \mathcal{N}_{t}} \lambda_{n} \max \left\{R_{\text {min }}^{w}-\rho\left[r_{t}\left(\mathbf{x}, \boldsymbol{\xi}_{s, t}\right) \mid \mathcal{S}_{n}\right], 0\right\}\right]
$$

Note that the second term of (6-8) accounts for an exact penalty term for a cash flow violating constraints (6-3) in the original problem. However, it is worth highlighting that for very small values of $\boldsymbol{\lambda}=\left[\lambda_{1}, \ldots, \lambda_{|\mathcal{N}|}\right]^{\prime}, \phi(\mathbf{x}, \boldsymbol{\lambda})$ could insufficiently penalize infeasible solutions, thereby assigning higher preferences to infeasible cash flows than to the cash flow associated with the optimal solution of the original problem (6-1)-(6-3). Nevertheless, in order to ensure 
that $\phi$ ranks all feasible solutions (that satisfy (6-3)) as the original problem, while keeping all infeasible solutions less preferable than any feasible solution (emulating a hard constraint), we need to select extremely high values for the penalty weights in $\boldsymbol{\lambda}$. For a general problem, this implies using $\lambda_{n}$ equal to infinity $\forall n \in \mathcal{N}$, which is equivalent to a perfect penalty. However, it is fair to argue that, in practice, high-quality solutions (close to the optimal) with very small violations are not "infinitely" worse than every feasible solution regardless of its expected revenue. In this sense, practical approaches replace the original problem (6-1)-(6-3) (with hard constraints) by its penalized version (6-4)-(6-7) (with soft constraints), provided the optimal solution of the original problem is ensured.

Aiming to define a complete preference functional ${ }^{1}$ that preserves the optimal solution of the original problem, a lower bound for the penalty vector $\boldsymbol{\lambda}$ can be found based on duality theory. To that end, note that problem (6-4)-(6-7) only differs from (6-1)-(6-3) by a vector of artificial variables $\boldsymbol{\nu}=\left[\nu_{1}, \ldots, \nu_{|\mathcal{N}|}\right]^{\prime}$, which is used to relax the risk constraints (6-3) and penalize their violations in the objective function (see (6-4)). In this case, if the optimal solution of the penalized problem $\left(\mathbf{x}^{*}, \boldsymbol{\nu}^{*}\right)$ is such that the reduced cost $\overline{\boldsymbol{c}}_{(\boldsymbol{\nu})}$ is nonpositive when evaluated with $\pi^{*}=\left[\pi_{1}^{*}, \ldots, \pi_{|\mathcal{N}|}^{*}\right]^{\prime}$ (the risk-constraints' optimal dual variables in the original problem), then $\mathbf{x}^{*}$ is optimal for the original problem too. This happens because, the original problem (6-1)-(6-3) is equal to its penalized version (6-4)-(6-7) when $\boldsymbol{\nu}^{*}=[0, \ldots, 0]^{\prime}$, i.e., if $\boldsymbol{\nu}$ is part of the vector of optimal nonbasic variables. As we know that $\boldsymbol{\pi}^{*}$ are nonpositive (due to the side of the inequality in (6-3)), the reduced cost of $\boldsymbol{\nu}$ allows us to derive the following lower bound for $\boldsymbol{\lambda}$ :

$$
\overline{\boldsymbol{c}}_{(\nu)}=-\boldsymbol{\lambda}+\left|\boldsymbol{\pi}^{*}\right|<\mathbf{0} \Longrightarrow \boldsymbol{\lambda}>\left|\boldsymbol{\pi}^{*}\right|
$$

Therefore, if we solve the original multistage problem, store $\boldsymbol{\pi}^{*}$, and use $\boldsymbol{\lambda}>\left|\boldsymbol{\pi}^{*}\right|$, we can use (6-8) to evaluate any $\mathbf{x}$, even those infeasible (not complying with the risk constraints). This will be important in our case study, where we will compare the solution of our multistage model with the solution obtained with a static two-stage version of it.

\section{3}

\section{Comparing Static and Dynamic Solutions}

The fact that static modeling fails to represent long-term uncertainties reveals two primary differences between it and the proposed approach:

\footnotetext{
${ }^{1} \mathrm{~A}$ complete preference functional is a functional capable of assigning a preference value
} to any cash flow regardless of its feasibility. 
1. Policy space: The two-stage problem has a reduced policy space, since it is not possible to represent "wait and see" strategies. Yet, the policy space from the two-stage problem is contained in the multistage one;

2. Future perspective: The multiple path outlook for multistage problems result in a more restricted problem for risk averse agents.

In a risk averse setting, if a solution $\left\{r_{s, t}\right\}$ satisfies the multistage constraint, it automatically satisfies the two-stage risk constraint. However, the inverse is not true: if $\left\{r_{s, t}\right\}$ satisfies the two-stage risk constraint, it will not necessarily meet the multistage one, as proven below.

Suppose $\left\{r_{s, t}\right\}$ satisfies the multistage constraint. Let's assume, for simplification purposes, and with no loss of generality, that $r_{s, t}$ is increasing in s. So:

$$
(1-a)^{-1}\left(\sum_{s \in \mathcal{S}_{n}} P_{s}\right)^{-1} \sum_{s \in \mathcal{S}_{n, 1}} P_{s} r_{s, t} \geq R_{\text {min }}^{w} \quad \forall n \in \mathcal{N}_{t}, t \in \mathcal{T}(6-10)
$$

where $\mathcal{S}_{n, 1}$ is so that:

$$
\sum_{s \in \mathcal{S}_{n, 1}} P_{s}=(1-\alpha) \sum_{s \in \mathcal{S}_{n}} P_{s}
$$

Therefore, $\mathcal{S}_{n, 1}$ is a subset of the indexes associated with the CVaR, corresponding to the set of scenarios with smaller values of $r_{s, t}$, and whose sum of corresponding probabilities is equal to $(1-\alpha)$.

Adding (6-10) and (6-11) along nodes $n \in \mathcal{N}_{t}$, and using $\sum_{s \in \cup_{n} \mathcal{S}_{n}} P_{s}=1$, for each $t$ we have:

$$
(1-a)^{-1} \sum_{s \in \cup_{n} \mathcal{S}_{n, 1}} P_{s} r_{s, t} \geq R_{\min }^{w}
$$

and

$$
\sum_{s \in \cup_{n} \mathcal{S}_{n, 1}} P_{s}=(1-\alpha)
$$

Hence, the two-stage CVaR constraint is met. On the other hand, if $\left\{r_{s, t}\right\}$ is a two-stage solution, it does not necessarily meet the multistage limits, as illustrated in the following example.

Ex: $\mathcal{S}=\{1,2,3,4,5,6\} ; \mathcal{S}_{1}=\{1,2,3\} ; \mathcal{S}_{2}=\{4,5,6\}$

$r_{s}=\{1,2,3,4,5,6\} ; \alpha=2 / 3 ; R_{\text {min }}=1.5$.

- Two-stage constraint: $C V a R=\frac{1+2}{2}=1.5 \geq R_{\text {min }}$

- Multistage constraint: $C V a R_{1}=1 \leq R_{\text {min }}$.

Practical consequences of this issue are addressed in chapter 7 . 


\section{Case Study}

In this section, a practical case study illustrates the applicability of the tool with real data from the Brazilian power sector. Although this study focuses on Brazil, other electricity markets, both centralized and liberalized, can also be considered. Furthermore, in order to demonstrate the effectiveness and benefits of the dynamic solution, the suggested formulation was contrasted with the state-of-the-art static approach, similar to the one found in [5] and [25], and different sensitivity solutions were analyzed using the performance measure described in Section 6.

Finally, all tests were conducted using the Julia programming language and solved with FICO Xpress 8.11, on an Intel Core i7-10510U processor at $1.80 \mathrm{GHz}$ with $16 \mathrm{~GB}$ of RAM. The total execution time to solve for the multistage problem was of 1.14 seconds, while the two-stage benchmark took 1.11 seconds.

\section{1 \\ Input Data}

This case study considers a $160 \mathrm{MW}$ wind generator in the northeastern area (Rio Grande do Norte) of the Brazilian power system with 100 avgMW long-term average annual generation and null unitary variable cost.

We use the framework introduced in Section 3.1 to jointly simulate a set of 200 independent scenarios of correlated renewable generation and spot prices with hourly granularity. Figure 7.1 shows the expected generation and spot price for the 4-week time frame used in this study. Besides the highly volatile prices, note that price peaks coincide with moments of low generation, which is an important characteristic of systems with high renewable penetration, as shown in [19] and [20]. Thus, the price and quantity risk renewable generators are subject to once inserted in this new reality is properly reflected. The complete data set is available in [50].

To represent long-term uncertainties, a tree structure was generated according to Section 3.3.1 using a quicksort algorithm for clustering. The 4stage tree framework resulted in a total of 23 nodes and 8 leaves, each leaf containing 25 scenarios. Graphic representation can be seen in Figure 7.3. The 


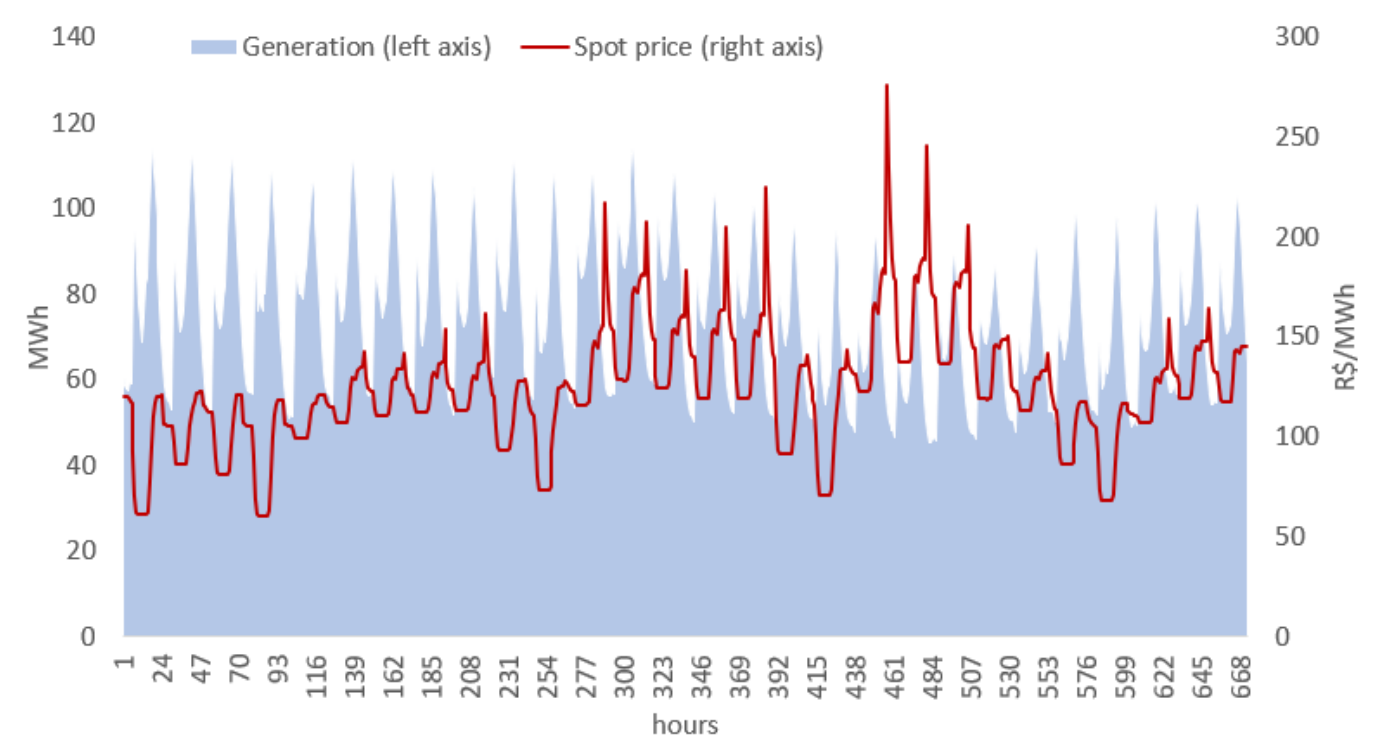

Figure 7.1: Expected values of wind power generation and spot prices.

connections between the root (node 1) and leaf nodes (nodes 16 to 23) produce eight tree paths, ordered from high to low prices, namely: "Very high", "High", "Mid+", "Base+", "Base-", "Mid-", "Low", "Very low".

The contracting opportunities are displayed in Figure 7.2, which contains all possibilities of forward contracting in the multistage framework, considering different maturities, start dates, and duration (defining a delivery horizon) within the considered month. In this figure, the circles represent the contract negotiation date, while the dashed arrows show delivery terms. There is a total of twenty numbered contracts, resulting in over a million $\left(2^{20}\right)$ different asset portfolio combinations for the following month. However, note that in a two-stage setting, only contracts negotiated in $t=1$ are available, reducing the set of forward contracts in half as, in such approach $\mathcal{C}=$ $\{1,2,3,4,11,12,13,17,18,20\}$. It is assumed all contracts are liquid and the negotiations are marginal and feasible to be implemented.

According to Section 3.3.2, forward prices were calculated for each node of the tree. To do so, two approximations were used, since we are applying this approach in a short-term horizon, for a month in weekly basis. First, we assumed that $S_{t} \approx \mathbb{E}\left[\frac{1}{\tau_{c}^{\text {end }}-\tau_{c}^{\text {start }}} \sum_{\tau=\tau_{c}^{\text {start }}}^{\tau_{c}^{\text {end }}} S_{s, \tau} \mid S_{t}\right]$ for all contracts. Second, we used the time series of forward prices with monthly delivery period $(\mathrm{M}+0)$ as a proxy for all intra-month forward prices, since these are the shortest contracts with a significant sample size in Brazil. Based on these approximations, we estimated the following regression model (obtaining an $R^{2}=0.96$ ) for the 


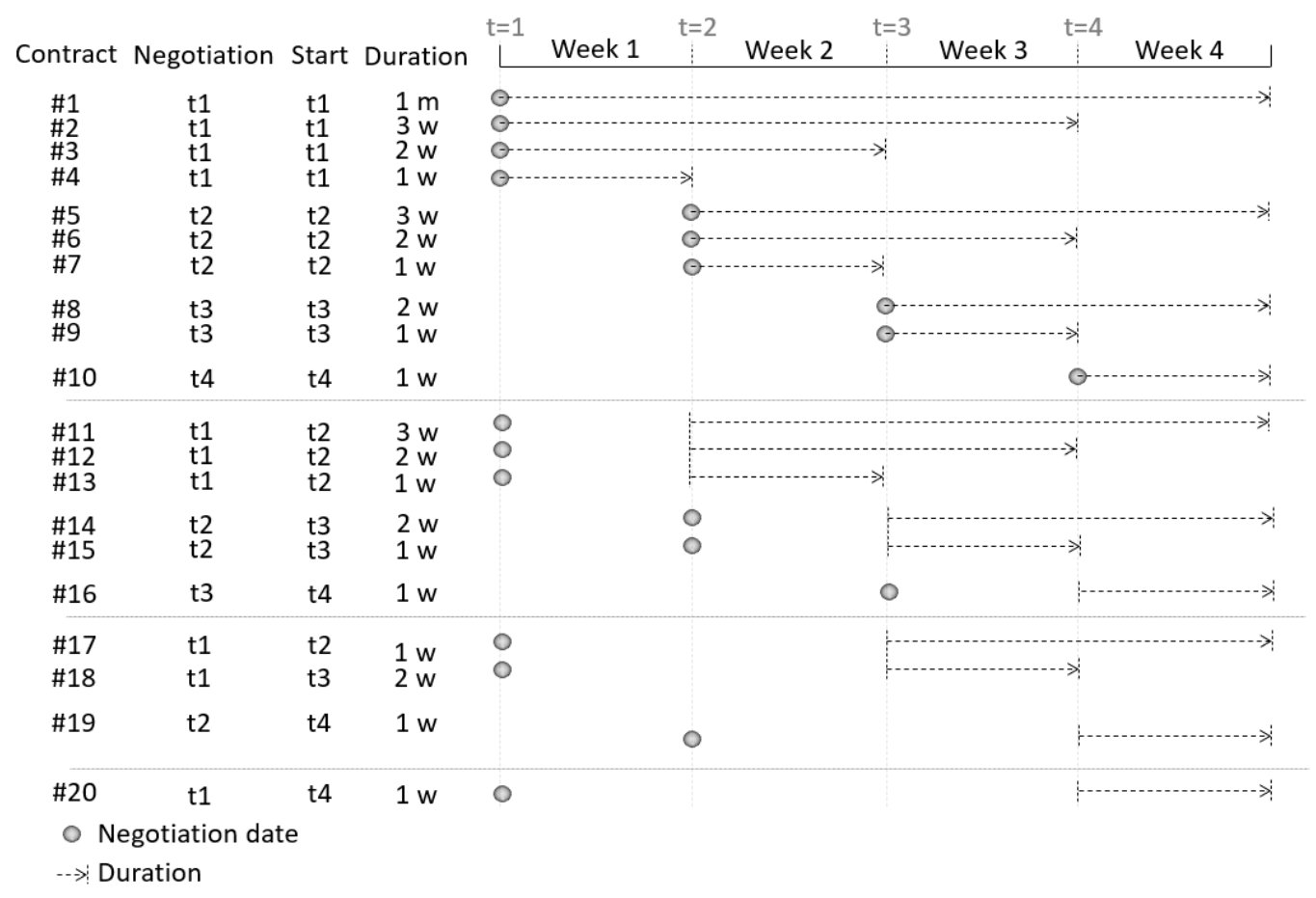

Figure 7.2: Weekly and monthly forward contracts.

spread:

$$
\begin{array}{r}
\hat{\Delta}_{t}=-0.07 S_{t}+15.31 . \\
\text { p-value }=(0.01) \quad(0.01)
\end{array}
$$

Thus, using our first approximation and the above regression, based on (3-1) we derived the expression of forward prices $\forall c \in \mathcal{C}$ and $\forall n \in \mathcal{N}_{\tau_{c}}$ as follows:

$$
F_{c, n}=0.93 \mathbb{E}\left[\frac{1}{\tau_{c}^{\text {end }}-\tau_{c}^{\text {start }}} \sum_{\tau=\tau_{c}^{\text {start }}}^{\tau_{c}^{\text {end }}} S_{s, \tau} \mid \mathcal{S}_{n}\right]+15.31
$$

Regarding the risk-averse policy, in this case study decisions must comply with the following risk limits: 1) stage-wise limit equal to $R_{m i n}^{w}=500 \mathrm{kR} \$$, with $90 \%$ confidence, in constraint (5-8), 2) a monthly aggregated limit equal to $R_{\text {min }}^{l}=3,000 \mathrm{kR} \$$, with $90 \%$ confidence, in constraint (5-11)), and 3) maximum one-period drawdown limit equal to $\theta=300 \mathrm{kR} \$$ in constraint $(5-13))$.

\section{2}

\section{Trading Strategy and Numerical Results}

Figure 7.3(a) shows the resulting contracting strategy for each week $(t=1, \ldots, 4)$ and tree node. The static contracting strategy obtained with 


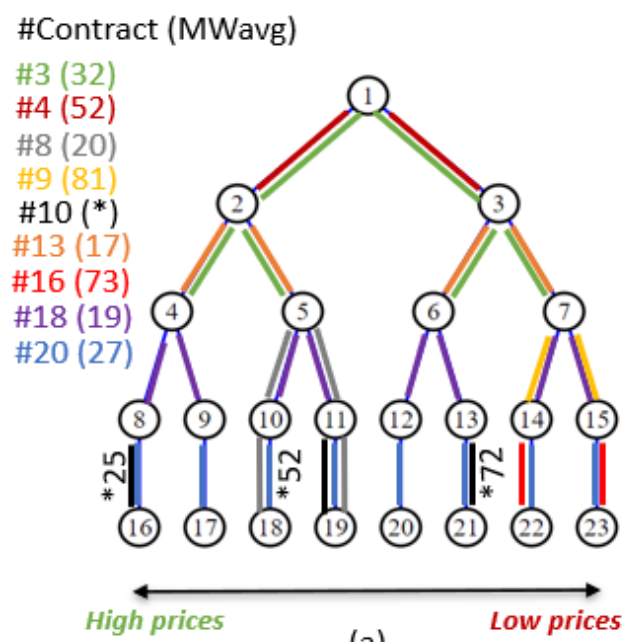

(a)

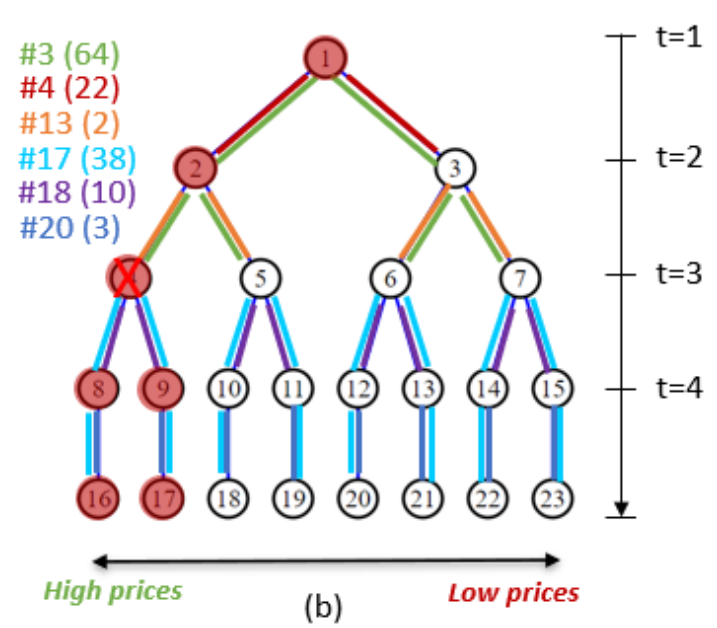

(b)

Figure 7.3: Dynamic (a) and static (b) trading strategies under a multistage perspective.

a two-stage version of the model is also shown in Figure 7.3(b). The static strategy is obtained with a particularization of the tree structure, where only one node per stage is allowed and all scenarios belong to every node. However, both the dynamic (multistage) and the static (two-stage) contracting strategies are then evaluated under the more realistic multistage perspective, i.e., selected contracts and constraints are evaluated in the tree structure. Selected contracts and their optimal volumes are shown in the captions according to their specifications in Figure 7.2, while nodes highlighted in red indicate paths where the multistage $90 \%-\mathrm{CVaR}$ constraints are violated.

Table 7.1 depicts a summary of statistics from three trading strategies, namely, the dynamic (rows 2-9), static (row 10), and uncontracted spot-based benchmark (row 11). Columns 2 and 3 present the expected revenue and the 90\%-CVaR for the whole month, columns 4 and 5 present the worst week 90\%-CVaR and drawdown, respectively. In column 1, rows 2-9 label the tree path for which the statistics relate, in the dynamic strategy case. It is clear from the last row that the benchmark strategy, in which the trading company relies solely on the spot market, does not comply with the risk policy.

The dynamic approach however, explores conditional information to dynamically manage the risk through a diversified portfolio of contracts. Hence, the agent is recommended to sell 44.75 to 54.28 avgMW of energy through bilateral contracts, depending on the evolution of prices. From the available 100 avgMW (67200 MWh in 4 weeks), $45 \%$ is sold in contracts settled today (See Figure 7.3, sum of $\mathcal{C}=\{3,4,13,18,20\}=\frac{32 \frac{M W h}{h} \cdot 336 h+(52+17+19+27) \frac{M W h}{h} \cdot 168 h}{67200}=$ $44.75 \%), 55 \%$ is left for future reassessment, and the difference between the 
Table 7.1: Statistical strategy results by path

\begin{tabular}{|c|c|c|c|c|c|}
\hline Path & $\begin{array}{c}\text { Average } \\
\text { Revenue } \\
(\mathrm{MR} \$)\end{array}$ & $\begin{array}{l}90 \%- \\
\text { CVaR } \\
(\mathrm{MR} \$)\end{array}$ & $\begin{array}{c}\text { Lowest } \\
90 \%-\mathrm{CVaR} \\
(\mathrm{MR} \$)\end{array}$ & $\begin{array}{l}\text { Highest } \\
\text { drawdown } \\
(\mathrm{MR} \$)\end{array}$ & $\begin{array}{l}\text { Contracted } \\
\text { amount } \\
\text { (avgMW) }\end{array}$ \\
\hline Very high & 7.11 & 3.01 & \multirow{8}{*}{0.50} & \multirow{8}{*}{0.30} & 45.47 \\
\hline High & 7.26 & 3.24 & & & 44.75 \\
\hline Mid+ & 6.95 & 3.81 & & & 47.23 \\
\hline Base+ & 6.72 & 5.00 & & & 48.87 \\
\hline Base- & 4.78 & 3.02 & & & 44.75 \\
\hline Mid- & 5.19 & 3.89 & & & 46.95 \\
\hline Low & 5.01 & 4.17 & & & 54.28 \\
\hline Very low & 5.60 & 4.89 & & & 54.28 \\
\hline Static & 6.05 & 3.00 & 0.50 & 0.30 & 60.31 \\
\hline Spot & 5.93 & 2.17 & 0.45 & 1.39 & - \\
\hline
\end{tabular}

actual generation and the committed energy is sold in the spot market. In general, higher contract levels are observed in lower price paths, which is due to lower spreads in the forward market as per (7-1). Expected values range from 7.12 $\mathrm{MR} \$$ (in higher price paths) to $4.78 \mathrm{MR} \$$ (in the base low path). The dynamic policy, by definition, complies with the risk policy. Interestingly, all three risk constraints have at least one path in which they are binding, and every path has at least one binding constraint.

On the other hand, the static solution locks in, today, prices for approximately $60 \%$ of the trading energy, which corresponds to a 60 avgMW commitment for the following month. Given the stochastic nature of the results, a very interesting way of visualizing the value of each solution is through the inverse cumulative probability distribution (quantile function) of their respective accumulated revenues. Figure 7.4 show these results from the root node, in which all 200 scenarios are foreseen.

It is noteworthy that both solutions have the same monthly expected revenue of $6.05 \mathrm{MR} \$$, i.e, the same resulting objective function value. Furthermore, the aggregated monthly CVaR constraint, calculated from the two-stage perspective (when seeing the tree with one node per stage only), does not appear to be binding in the dynamic solution, as opposed to the static one. However, the trading policy indicated by the latter does not necessarily meet risk constraints in every path.

As an alternative, in the multistage perspective, Figure 7.5 shows the 


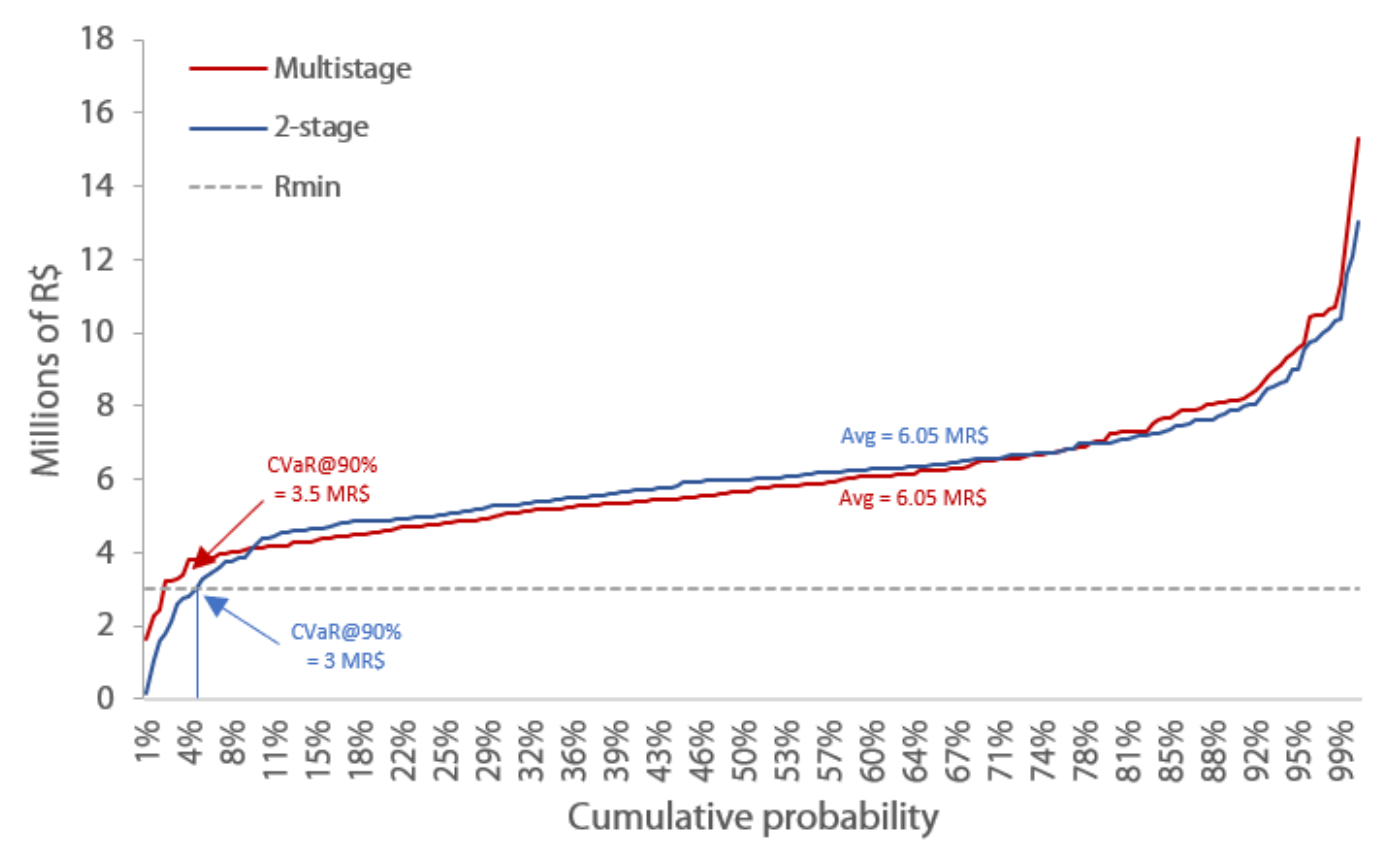

Figure 7.4: Monthly revenue quantile function for multistage and two-stage strategies.

inverse cumulative probability distribution function for the "Very high" tree path. In this case, the monthly $90 \%-\mathrm{CVaR}$ constraint is binding for the multistage solution, but is far from meeting the risk-policy limit in the static solution case (the $90 \%-\mathrm{M} \mathrm{CVaR}$ values $0.93 \mathrm{MR} \$, 70 \%$ lower than the limit). Other weekly and monthly constraint violations are found in the "Very high" (90\%-W CVaR of $144 \mathrm{kR} \$$ in week 3) and "High" (90\%-M CVaR of $2.6 \mathrm{MR} \$$ ) paths for the static solution.

\section{3}

\section{Assessing the Value of Solutions Under a Risk-aversion Profile}

In this analysis, we emulate a situation where the trading company, with a risk-preference induced by the optimal solution of the decision problem (5-1)-(5-13), can evaluate a variety of strategies. In this setting, the company must select the strategies to find solutions that may bring expected returns greater or equal to the optimal solution shown in 7.2. On this basis, we apply the performance measure described in section 6 while extending its scope to consider all risk constraints.

The first step is to obtain the preference functional, which can be done by finding the minimum penalties for each constraint violation from the multistage problem. For the maximum one-period drawdown, 600 multipliers were found, equivalent to the 200 scenarios times three stage transitions. These dual 


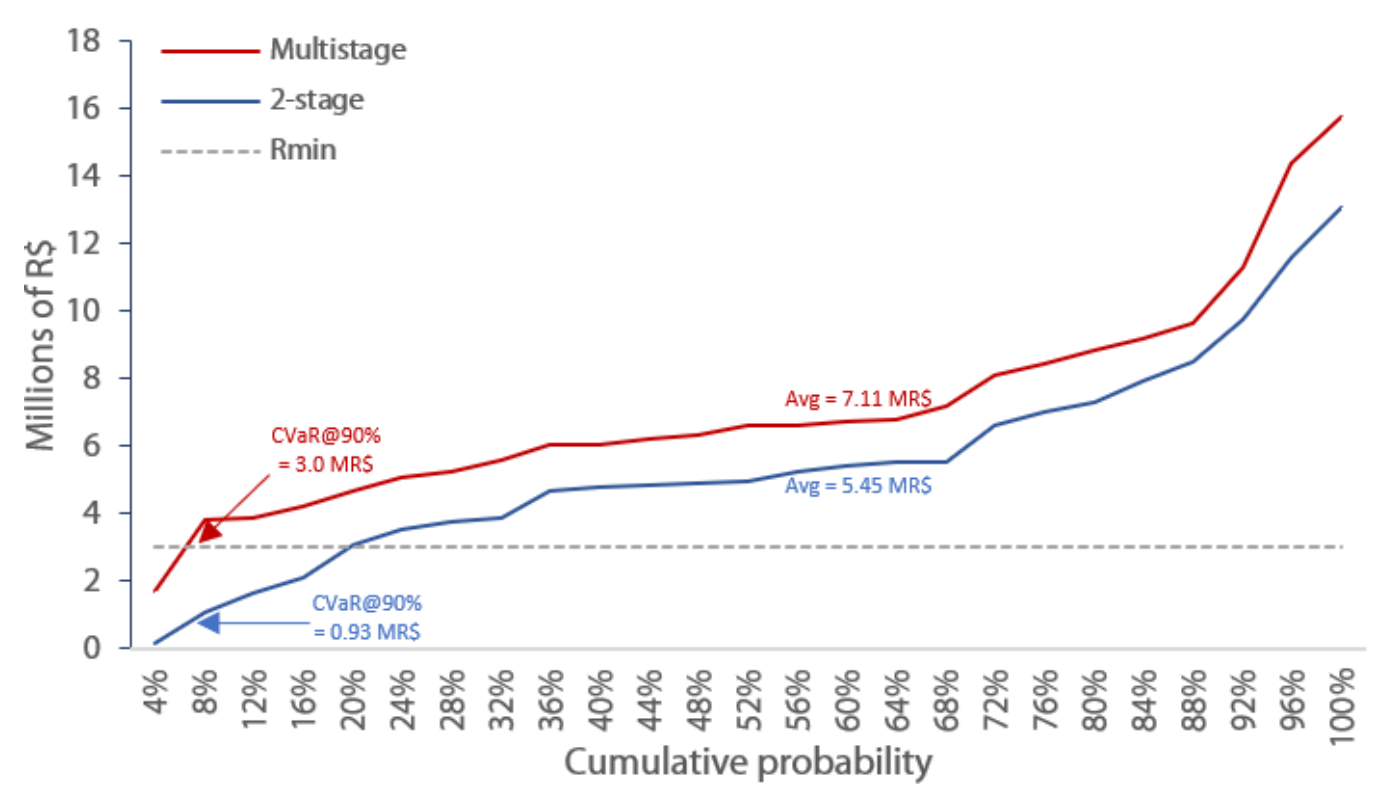

Figure 7.5: Monthly revenue quantile function for "Very high" path.

variables, $\eta_{s, t}$, defined lower bounds for the penalties between 0 to 1.11. As for the stage-wise W CVaR constraints, the 23 nodes defined lower bounds for the penalties between 0 to 0.06 in binding nodes. Lastly, for the monthly CVaR, eight tree paths generated penalties ranging between 0 to 1.37.

In this study, we generated two trading strategies based on the optimal static (two-stage) and dynamic (multistage) approaches, respectively, and conducted several sensitivity analysis. The results of each sensitivity is presented in a (column) block of Figure 7.6, whose lower captions indicate the risk constraints that were considered. So, from the left to right, risk constraints were gradually removed from the original problem set of three risk constraints. Each block contains two bars, whose total height are associated with the expected revenue for the dynamic and static strategies, respectively. The value of the preference functional applied to each strategy is displayed in light blue bars. The penalty values for the maximum drawdown, monthly (M CVaR), and weekly (W CVaR) constraints are depicted through dotted, dark-gray, and black bars, respectively. Note that, according to (6-8), the expected revenue is equal to the sum of the preference functional and violation penalties. Thus, we display the expected revenue value (in MR\$) on the top of each bar, whereas the value of the preference functional is shown inside the lowermost light blue bars (also in MR $\$$ ).

In the first (left) block of Figure 7.6, we can see the results of the dynamic and static approaches described in 7.2. As mentioned before, both solutions have the same expected revenue (6.05 MR $\$$ ). Nevertheless, a $420 \mathrm{kR} \$$ penalty is 


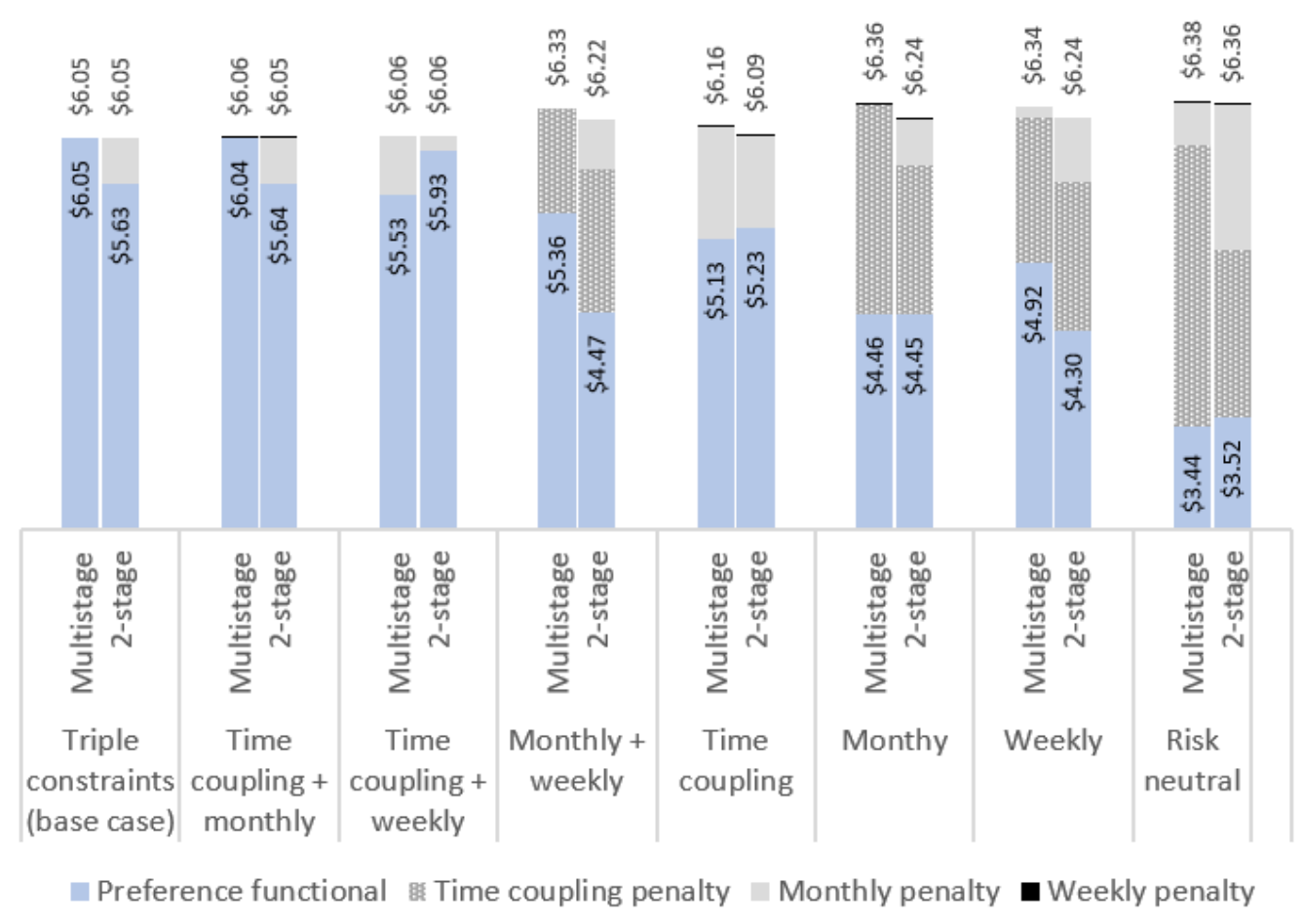

Figure 7.6: Preference functional.

incurred by the static solution due to monthly CVaR violations, which lowered the preference functional value of this solution by $7.0 \%$ in comparison to the multistage strategy. Thus, for the dynamic risk-preference introduced, $420 \mathrm{kR} \$$ can be regarded as the value of the multistage model.

On the other hand, the policy suggested by the dynamic solution disregarding weekly constraints (second block) indicates a value of 6.04 MR \$. This is less than $1 \%$ lower than the optimal dynamic strategy compliant to all constraints (first column). In this case, disregarding the weekly constraints allowed a $10 \mathrm{kR} \$$ increase in expected value, but at the cost of $20 \mathrm{kR} \$$ in violation penalties. Note that, as much as we relax constraints, the preference functional value decreases until it reaches the lowest value for the risk-neutral strategies, where all risk constraints are disregarded. In this framework, we are able to quantify the loss of preference (certainty equivalent) due to individual constraint violations. For instance, the drawdown risk constraint is responsible for the highest loss in preference, when compared to the other individual constraints. 


\section{8 \\ Conclusions}

This work presented a multistage stochastic model that can be used to assist risk-averse agents in defining their optimal dynamic involvement in forward contracts. The proposed model allows energy traders and producers to devise strategies that maximize revenue and hedge against price-and-quantity risks. We combined a dual-scale decision tree to jointly account for operational (hourly spot prices and renewable generation) and strategic (weekly forward prices) uncertainties. Furthermore, three time-consistent dynamic risk constraints (based on weekly and monthly conditional CVaR constraints, and maximum one-period drawdown) were proposed to define a risk policy. The representation of both uncertainties within a dynamic risk management framework has shown to have a relevant impact on trading strategies.

Results based on realistic data from the Brazilian power system show that static solutions, which are myopic in terms of the dynamics of risk constraints and "wait and see" contracting opportunities, tend to over contract and expose the company to market risks. In this context, when contrasted to the proposed dynamic strategy, results indicate that static strategies significantly violate risk limits in high-price trajectories. Thus, a preference functional was derived to assess the value of the multistage model. Furthermore, the proposed functional helped to quantify the value, in terms of the certainty equivalent, of each dynamic risk constraint. 


\section{Bibliography}

[1] Operador nacional do sistema. http://www.ons.org.br/paginas/ sobre-o-sin/o-sistema-em-numeros. Accessed: 2021-07-01.

[2] HIRTH, L.. The market value of variable renewables: The effect of solar wind power variability on their relative price. Energy economics, 38:218-236, Jul. 2013.

[3] MARKOWITZ, H.. Portfolio selection. The Journal of Finance, 7(1):7791, Mar. 1952.

[4] A.J.CONEJO; M.CARRIÓN ; J.M.MORALES. Risk management. In: Decision Making Under Uncertainty in Electricity Markets, volumen 153. International Series in Operations Research \& Management Science. Springer,Boston,MA, 2010.

[5] STREET, A.; BARROSO, L.; FLACH, B.; PEREIRA, M. ; GRANVILLE, S.. Risk constrained portfolio selection of renewable sources in hydrothermal electricity markets. Power Systems, IEEE Transactions on, $24: 1136$ - 1144, 092009.

[6] FANZERES, B.; STREET, A. ; BARROSO, L. A.. Contracting strategies for renewable generators: A hybrid stochastic and robust optimization approach. IEEE Transactions on Power Systems, 30(4):18251837, 2015.

[7] ALGARVIO, H.; LOPES, F.; SOUSA, J. ; LAGARTO, J.. Multi-agent electricity markets: Retailer portfolio optimization using markowitz theory. Electric Power Systems Research, 148:282-294, 072017.

[8] CAMARGO, L. A. S.; LEONEL, L. D.; RAMOS, D. S. ; STUCCHI, A. G. D.. A risk averse stochastic optimization model for wind power plants portfolio selection. In: 2020 INTERNATIONAL CONFERENCE ON SMART ENERGY SYSTEMS AND TECHNOLOGIES (SEST), p. 1-6, 2020.

[9] PASSOS, A. C.; STREET, A. ; BARROSO, L. A.. A dynamic real optionbased investment model for renewable energy portfolios. IEEE Transactions on Power Systems, 32(2):883-895, 2017. 
[10] KETTUNEN, J.; SALO, A. ; BUNN, D. W.. Optimization of Electricity Retailer's Contract Portfolio Subject to Risk Preferences. IEEE Transactions on Power Systems, 25, Feb. 2010.

[11] OTAOLA-ARCA, P.; GARCÍA-GONZÁLEZ, J.; MARIÑO, F. ; RIVERA, I.. Modeling of third party access tariffs and portfolio gas purchases of ccgts in the self-unit commitment problem. IEEE Transactions on Power Systems, 36(4):2771-2785, 2021.

[12] SHAPIRO, A.. On a time consistency concept in risk averse multistage stochastic programming. Operations Research Letters, 37:143-147, 052009.

[13] RUDLlof, B.; STREet, A. ; VAlLADÃO, D.. Time consistency and risk averse dynamic decision models: Definition, interpretation and practical consequences. European Journal of Operational Research, 234:743-750, 2014.

[14] VAlladÃO, D.; SILVA, T. ; POGGI, M.. Time-consistent riskconstrained dynamic portfolio optimization with transactional costs and time-dependent returns. Annals of Operations Research, 2018.

[15] GOREnStin, B.; CAMPOdÓNICO, N.; COSTA, J. ; PEREIRA, M.. Power System Planning Under Uncertainty. IEEE Transactions on Power Systems, 8, 1993.

[16] DEFOURNY, B.; ERNST, D. ; WEHENKEL, L.. Multistage stochastic programming: A scenario tree based approach to planning under uncertainty. LE, Sucar, EF, Morales, and J., Hoey (Eds.), Decision Theory Models for Applications in Artificial Intelligence: Concepts and Solutions. Hershey, Pennsylvania, USA: Information Science Publishing, 012011.

[17] HEITSCH, H.; ROEMISCH, W.. Scenario reduction algorithms in stochastic programming. Computational Optimization and Applications, 24:187-206, 012003.

[18] ARPÓN, S.; HOMEM-DE MELLO, T. ; PAGNONCELLI, B.. Scenario reduction for stochastic programs with conditional value-at-risk. Mathematical Programming, 170, 052018.

[19] ASTANeH, M. F.; CHEN, Z.. Price volatility in wind dominant electricity markets. In: EUROCON 2013, p. 770-776, 2013. 
[20] DONG, S.; LI, H.; WALLIN, F.; AVELIN, A.; ZHANG, Q.; YU, Z.. Volatility of electricity price in denmark and sweden. Energy Procedia, 158:4331-4337, 022019.

[21] BIÇEN, Y.. The price volatility and risks in the electricity market. 092019.

[22] KAUT, M.; MIDTHUN, K.; WERNER, A.; TOMASGARD, A.; HELLEMO, L. ; FODSTAD, M.. Multi-horizon stochastic programming. Computational Management Science, 11, 012014.

[23] CHEKHLOV, A.; URYASEV, S. ; ZABARANKIN, M.. Portfolio optimization with drawdown constraints. 042000.

[24] ROCKAFELLER, R. T.; URYASEV, S.. Optimization of conditional value-at-risk. J. Risk, 2(3):21-41, 2000.

[25] RAGUENET, E.; DIENE, O.. Decision support system for a portfolio of a hydroelectric company in the brazilian market. p. 1-6, 09 2019.

[26] IRENA. Innovation landscape brief: Increasing time granularity in electricity markets, 2019.

[27] PEREIRA, M.; PINTO, L.. Multi-stage stochastic optimization applied to energy planning. Mathematical Programming, 52:359-375, 1991.

[28] HULL, J.. Options, futures, and other derivatives. Pearson Prentice Hall, 9. ed., pearson internat. ed edition, 2015.

[29] Agência nacional de energia elétrica. http://www.aneel.gov.br/ sala-de-imprensa/-/asset_publisher/zXQREz8EV1Z6/content/id/ 22293545. Accessed: 2021-06-18.

[30] BeZerRA, B.; A.VeigA; BARROSO, L. A. ; PereirA, M.. Assessment of parameter uncertainty in autoregressive streamflow models for stochastic long-term hydrothermal scheduling. In: 2012 IEEE POWER AND ENERGY SOCIETY GENERAL MEETING, p. 1-8, 2012.

[31] DIAS, J. A.; MACHADO, G.; SOARES, A. ; GARCIA, J. D.. Modeling multiscale variable renewable energy and inflow scenarios in very large regions with nonparametric bayesian networks. 2020. 
[32] FRANSES, P. H.; PAAP, R.. Model selection in periodic autoregressions. Oxford Bulletin of Economics and Statistics, 56(4):421-439, 061994.

[33] PEREIRA, M.; OlIVEIRA, G.; COSTA, C. ; KELMAN, J.. Stochastic streamflow models for hydroelectric systems. Water Resources Research, 20(3):379-390, 1984.

[34] D.W.SCOTT. Kernel density estimation revisited. Nonlinear Analysis, Theory, Methods \& Applications, 1(4):339-372, 1917.

[35] QIJUN, T.; CHENGFU, W.; JUN, L. ; ZHENGTANG, L.. Research on modeling spatiotemporal correlation of wind power forecast error on multiple wind farms based on copula theory. In: 2017 2ND INTERNATIONAL CONFERENCE ON POWER AND RENEWABLE ENERGY (ICPRE), p. 447-450, 2017.

[36] CRUZ, A.; MUÑOZ, A.; ZAMORA, J. L. ; ESPÍNOLA, R.. The effect of wind generation and weekday o Spanish electricity spot price forecasting. Electric Power Systems Research, 2011.

[37] AASLID, P.; KORPÅS, M.; BELSNES, M. M. ; FOSSO, O. B.. Pricing electricity in constrained networks dominated by stochastic renewable generation and electric energy storage. Electric Power Systems Research, 197, 2021.

[38] SONG, Y.-Y.; LU, Y.. Decision tree methods: applications for classification and prediction. Shanghai archives of psychiatry, 27:130-5, 042015.

[39] PARPAS, P.; USTUN, B.; WEBSTER, M. ; TRAN, Q.. Importance sampling in stochastic programming: A markov chain monte carlo approach. INFORMS Journal on Computing, 27:358-377, 042015.

[40] XU, D.; CHEN, Z. ; YANG, L.. Scenario tree generation approaches using k-means and lp moment matching methods. Journal of Computational and Applied Mathematics, 236:4561-4579, 112012.

[41] RUBASHEUSKI, U.; OPPEN, J. ; WOODRUFF, D.. Multi-stage scenario generation by the combined moment matching and scenario reduction method. Operations Research Letters, 42, 072014.

[42] KIESEL, R.; PARASCHIV, F. ; SÆTHER $\varnothing$, A.. On the construction of hourly price forward curves for electricity prices. Computational Management Science, 022018. 
[43] CAllegaro, G.; MAZZORAN, A. ; SGARRA, C.. A self-exciting modelling framework for forward prices in power markets. 10 2019.

[44] CAVAlieRE, M.; GRANVILLE, S.; OliveIRA, G. ; PEREIRA, M.. A forward electricity contract price projection: A market equilibrium approach. 042019.

[45] BOTTERUD, A.; KRISTIANSEN, T. ; ILIC, M. D.. The relationship between spot and futures prices in the nord pool electricity market. Energy Economics, 32(5):967-978, 2010.

[46] ZHU, X.; YU, Z.; ; LIU, X.. Security constrained unit commitment with extreme wind scenarios. Journal of Modern Power Systems and Clean Energy, 8(3):464-472, 2020.

[47] ARTZneR, P.; DELBAEN, F.; JEAN-MARC, E. ; HEATH, D.. Coherent measures of risk. Mathematical Finance, 9:203 - 228, 071999.

[48] GOLDBERG, L.; MAHMOUD, O.. On a convex measure of drawdown risk. 2014.

[49] STREET, A.. On the conditional value-at-risk probabilitydependent utility function. Theory and Decision, 68(1):49-68, 2010.

[50] ARANHA, A. S.. Study data risk constrained optimal trading strategies under short- and long-term uncertainties, 2021. 